Original Research Paper

\title{
Exploratory Study on the Fracture Resistance of Cast Glass
}

\author{
${ }^{1}$ Telesilla Bristogianni, ${ }^{2}$ Faidra Oikonomopoulou, ${ }^{2}$ Fred Veer and ${ }^{1}$ Rob Nijsse \\ ${ }^{I}$ Faculty of Civil Engineering and Geosciences, TU Delft, Delft, The Netherlands \\ ${ }^{2}$ Faculty of Architecture and the Built Environment, TU Delft, The Netherlands
}

Article history

Received: 28-03-2021

Revised: 01-05-2021

Accepted: 10-05-2021

Corresponding Author:

Telesilla Bristogianni

Faculty of Civil Engineering

and Geosciences, TU Delft,

Delft, The Netherlands

Email: t.bristogianni@tudelft.nl

\section{Introduction}

The use of cast glass as a structural material has been explored in several architectural projects such as the Atocha Memorial in Madrid (Paech and Goppert, 2008), the Optical Glass House in Hiroshima (Nakamura, 2012), the Crystal Houses in Amsterdam (Oikonomopoulou et al., 2018a; 2018b) and the Robotic Glass Vault in London (Parascho et al., 2020). The success of these projects showcases the aesthetical and structural potential of cast glass, intriguing the architectural and engineering community to consider cast glass as a promising building material.

Yet, as the interest in the structural application of cast glass, made either out of pure batch materials or recycled

\begin{abstract}
The emerging interest in the architectural applications of cast glass components reveals a knowledge gap on the mechanical properties of cast glass. Apart from its chemical composition, cast glass is characterized by its manufacturing history and thermal profile, often inheriting a set of defects that define its properties. The role that inhomogeneities in the bulk of us glass components have on the strength of the final product is also entain. Systematic testing is therefore necessary for the safe structural application of cast glass. Towards this direction, the presented research aims indenter. Cubic specimens with $50 \mathrm{~mm}$ sides are kiln-cast at low forming temperatures, employing a variety of silicate-based cullet and firing schedules and their inherent defects are documented. The results of the splitting tests show that the borosilicate specimens fail at the highest splitting force, followed by the soda lime float specimens, while the fused or porous specimens have a significantly lower resistance to fracture. The strength order of the various glasses, as this results from the splitting tests- is opposite to that found earlier in four-point bending tests, due to the different fracture mechanisms activated. The fracture resistance of a glass specimen is governed, first by its ability to deform around the indenter to relief the Thus, good balance between glass network flexibility and high bond dissociation energy is required, explaining why the tested homogeneous borosilicate and soda lime glasses are more resistant than the modified soda lime compositions with high alkali content. In addition, the fractographic analysis indicates that the non-stress inducing flaws in the bulk have a
\end{abstract}

Keywords: Cast Glass, Fracture Resistance, Glass Inhomogeneities, Glass Brittleness, Crack Initiation and Propagation waste cullet, increases, the need of establishing suitable testing methods for voluminous glass components becomes imperative. Widely used experimental procedures such as the four-point bending test give valuable indications about the strength of cast glass (Bristogianni et al., 2020), but are mainly linked to the quality of the glass surface and ignore the bulk properties. In addition, the subjection of a glass element to a far-field stress involves different fracture mechanisms than those involved in contact loading. Cast glass components, however, are more often employed in compressive load-bearing structures (e.g., walls, arches), being thus subjected to contact peak stresses rather than bending stresses. In this case, the fracture resistance of cast glass is influenced by two processes: 
Stage a, the ability of the loaded glass surface zone to resist crack initiation by deformation and stage $b$, the ability of the glass matrix surrounding the eventually initiated crack to resist unstable crack propagation. Understanding the fracture resistance of ceramics to contact loading is commonly approached by testing two distinct material properties; Hardness (stage a, resistance to deformation) and Fracture Toughness ${ }^{1}$ (stage b, resistance to catastrophic crack propagation).

In this study, a new experimental approach is developed that tests the combined fracture resistance of cast glass, from crack initiation to total component failure, with the aim of providing direct indications about the brittleness of cast glass. More specifically, a spitting test is proposed, by introducing increasing pressure on a cast glass cubic specimen with a longitudinal sharp indenter, until complete fracture. The experiment borrows elements from the Diametral Compression experiment (Brazilian Disk), which is commonly used for the evaluation of the tensile strength of concrete (ASTM C 496, 2011). Diametral compression testing in glass is not common practice, yet several examples concerning the testing of glass spheres (Kschinka et al., 1986), or glass discs (Nyounguè et al., 2016; Sheikh et al., 2019) are reported in literature. Although the Brazilian Disk test aims to subject the core of the tested cylinder in uniform tension, Mellor and Hawkes (1971) report regarding their experiments on glass that fracture started from the surface, due to machining flaws that were more severe than the defects in the bulk.

The splitting test proposed in this study, simplifies the specimen's casting and post-processing and increases its dimensional accuracy, by changing the cylindrical shape into a cube. Further on, it simplifies the support conditions at the universal testing machine, by introducing the concentrated linear force at only one side (bottom) of the specimen. Crack initiation starts from this contact zone and leads to the splitting of the specimen into two fragment's once the load reaches a critical value. The two fragmented surfaces allow studying the interaction of the crack front with singularities present in the cast glass mesostructure. Although such defects in the bulk are not directly activated by the splitting test, their interaction with the crack path can expose information about their contribution to the fracture behaviour of cast glass (e.g., formation of weak zones, arrest of crack propagation). Such information is particularly relevant for the testing of voluminous cast glass components made out of waste glass at high casting viscosities, where a high population of defects are expected to be present in the mesostructure.

\footnotetext{
${ }^{1}$ Typical fracture toughness test methods such as the Single-Edged Precracked Beam (SEPB) assume a given starting crack size upon which stable crack growth and catastrophic propagation build upon. Yet, regarding the chance of a crack to initiate, some glasses will show more susceptibility
}

\section{Materials and Methods}

\section{Specimen Preparation and Analysis}

Cast glass specimens with different degrees of inhomogeneity, are produced for the purposes of the splitting test, using recycled glass cullet. The $50 \mathrm{~mm}$ cubic glass specimens are kiln-cast in triplets per glass type and firing schedule. Relatively low forming temperatures $\left(870-1120^{\circ} \mathrm{C}\right)$ and corresponding high viscosities $\left(10^{6}-10^{3.5}\right.$ $\mathrm{dPa}$ s) are employed, intensifying the occurrence of defects in the glass surface and mesostructure. The glass cullet employed involves common silicate based glasses such as Soda Lime Silicate "SLS" (Float with/without coatings, container glass, modified) and Borosilicate. X-Ray Fluorescent (XRF) analyses are conducted with a Panalytical Axios Max WDXRF spectrometer, in order to determine the chemical composition of the used glass cullet and of possible present contaminants (e.g., mirror coating).

Various different cullet sizes/shapes are used in this study, which are either deposited directly (Fig. 1) in silica-plaster investment moulds (Crystalcast M248) or fed in terracotta flowerpots placed above the moulds. The moulds and terracotta pots are placed inside a ROHDE ELS 200S electric kiln, heated up to the forming temperature and controllably cooled down to room temperature according to the selected firing schedule.

Below the list of different firing schedules used for the kiln-casting of the samples can be found (Table 1):

- $\quad 10 \mathrm{~h}$ dwell time at $1120^{\circ} \mathrm{C}$ top temperature $\left(870^{\circ} \mathrm{C}\right.$ for B270 glass), $-160^{\circ} \mathrm{C} / \mathrm{hr}$ cooling rate down to annealing point (referred to as "fast-cooling" in this article)

- $\quad 2 \mathrm{~h}$ dwell time at $1120^{\circ} \mathrm{C}$ top temperature, with a cooling rate of $-50^{\circ} \mathrm{C} / \mathrm{hr}$ down to annealing point (referred to as "slow-cooling")

- $\quad 10 \mathrm{~h}$ dwell time at $970^{\circ} \mathrm{C}$ top temperature, with a cooling rate of $-160^{\circ} \mathrm{C} / \mathrm{hr}$ down to annealing point (referred to as "fused")

- $\quad 3 \mathrm{~h}$ dwell time at $1050 / 1070^{\circ} \mathrm{C}$ top temperature, with a cooling rate of $-160^{\circ} \mathrm{C} / \mathrm{hr}$ down to the heat treatment point between $760-890^{\circ} \mathrm{C}$, (referred to as "heat-treated")

All samples are annealed for $10 \mathrm{hr}$ at their corresponding annealing temperature. Upon cooling, the top and bottom surface of the specimens are ground and polished using a Provetro flat grinder and diamond abrasive discs in sequence of $60,120,200,400$ and 600 grit.

In order to provide a reference, a series of $50 \mathrm{~mm}$ cubic specimens are prepared using industrially produced glass in the following manner:

to external damage due to their chemical composition, insufficient annealing, intrinsic flaws or machining and handling damage. Such glasses in real-world applications will have higher chances to failure, thus the need to review the resistance to crack initiation together with the fracture toughness. 
- $10 * 50 * 50 \mathrm{~mm}$ float glass panes glued with UV-curing acrylate DELO 4468. The cut edges are polished as described above, while the longitudinal glossy surface is left in its as received condition (fine polishing, occasional scratches)
- $50 \mathrm{~mm}$ cubes cut out of Poesia ${ }^{2}$ cast glass bricks. Clear and hazy cast glass brick variants are used. The cubes are either left to their as received glossy condition, or polished at 600 grit, as described above

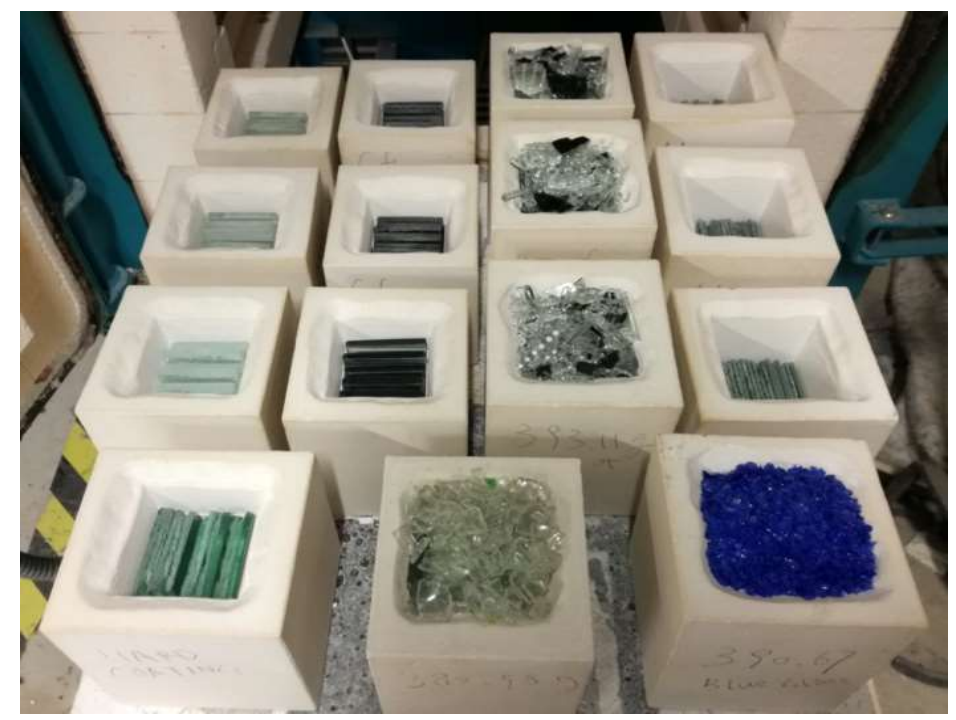

Fig. 1: Arrangement of glass cullet in disposable silica plaster moulds

Table 1: (part 1). Casting parameters implemented for the preparation of the glass specimens

\begin{tabular}{|c|c|c|c|c|c|c|c|}
\hline Glass Type & Specimen description & Source & $\begin{array}{c}\text { Chemical composition } \\
\text { of glass and } \\
\text { contaminants^ }(\text { main } \\
\left.\text { compounds in } \mathrm{wt}^{2} \%\right)\end{array}$ & $\begin{array}{c}\text { Forming temperature } \\
\text { in }{ }^{\circ} \mathrm{C}(10 \mathrm{~h} \text { dwell } \\
\text { unless differently } \\
\text { specified })\end{array}$ & $\begin{array}{l}\text { Cooling rate } \\
\left({ }^{\circ} \mathrm{C} / \mathrm{hr}\right) \text {, heat } \\
\text { treatment if } \\
\text { applicable }\end{array}$ & $\begin{array}{l}\text { Annealing } \\
\text { temperature in } \\
{ }^{\circ} \mathrm{C}(10 \mathrm{~h} \text { dwell })\end{array}$ & $\begin{array}{l}\text { Cullet size, } \\
\text { shape and } \\
\text { array }\end{array}$ \\
\hline \multirow{5}{*}{$\begin{array}{l}\text { Soda Lime } \\
\text { Silica } \\
\text { (Float } \\
\text { Glass) }\end{array}$} & FT float* & IFS-SGT & $\begin{array}{c}75.4 \% \mathrm{SiO}_{2}, 12.4 \% \\
\mathrm{Na}_{2} \mathrm{O}, 7.6 \% \mathrm{CaO} \\
4 \% \mathrm{MgO} \\
0.4 \% \mathrm{Al}_{2} \mathrm{O}_{3}\end{array}$ & 1120 & -160 & 560 & \\
\hline & $\begin{array}{c}\text { Float } 10 \mathrm{~mm} * 5 \\
\text { layers }\end{array}$ & \multirow[t]{2}{*}{ IFS-SGT } & $\begin{array}{c}72.4 \% \mathrm{SiO}_{2}, 12.3 \% \\
\mathrm{Na}_{2} \mathrm{O}, 9.9 \% \mathrm{CaO} \\
4.1 \% \mathrm{MgO} \\
0.6 \% \mathrm{Al}_{2} \mathrm{O}_{3}\end{array}$ & 1120 (2hr) & -160 & 560 & \\
\hline & Low-iron float & & & 1120 & -160 & \multirow{3}{*}{560} & \\
\hline & $\begin{array}{l}\text { Low-iron float, } \\
\text { heat-treated }{ }^{* *}\end{array}$ & \multirow[t]{2}{*}{ Cricursa } & $\begin{array}{c}74 \% \mathrm{SiO}_{2}, 12.7 \% \\
\mathrm{Na}_{2} \mathrm{O}, 8.4 \% \mathrm{CaO}, \\
4.2 \% \mathrm{MgO}, \\
0.55 \% \mathrm{Al}_{3}\end{array}$ & $1050(3 \mathrm{~h})$ & $\begin{array}{c}-30 \\
\text { Heat treatment, } \\
1: 10 \mathrm{~h} 860^{\circ} \mathrm{C} \\
2: 10 \mathrm{~h} 840^{\circ} \mathrm{C}\end{array}$ & & \\
\hline & $\begin{array}{l}\text { Low-iron float } \\
\text { powdered, } \\
\text { fused } * * *\end{array}$ & & & 970 & -160 & & \\
\hline
\end{tabular}

${ }^{\wedge}$ All composition data derived by XRF measurements conducted with a Panalytical Axios Max WD-XRF spectrometer by Ruud Hendrikx (TU Delft, 3 mE), apart from the $\mathrm{SiO}_{2} / \mathrm{B}_{2} \mathrm{O}_{3}$ ratio in DURAN Schott derived from (Heimerl et al., 1999) and the $\mathrm{SiO}_{2} / \mathrm{B}_{2} \mathrm{O}_{3}$ ratio in Poesia glass derived from personal communication with the company

* The labelling "FT Float" refers to the use of Fully Tempered float glass shards as cullet. The final kiln-cast components are annealed and the thermal history of the shards is erased

** Sample prepared by Lei (2019) as part of her MSc work

*** Sample prepared by Guilia Maria Anagni, as part of her MSc work (Anagni et al., 2020)

${ }^{2}$ Poesia is the producer of the cast glass bricks employed for the building of the Crystal Houses Façade (Oikonomopoulou et al., 2018a). 
Telesilla Bristogianni et al. / International Journal of Structural Glass and Advanced Materials Research 2021, Volume 5: 195.225 DOI: $10.3844 /$ sgamrsp.2021.195.225

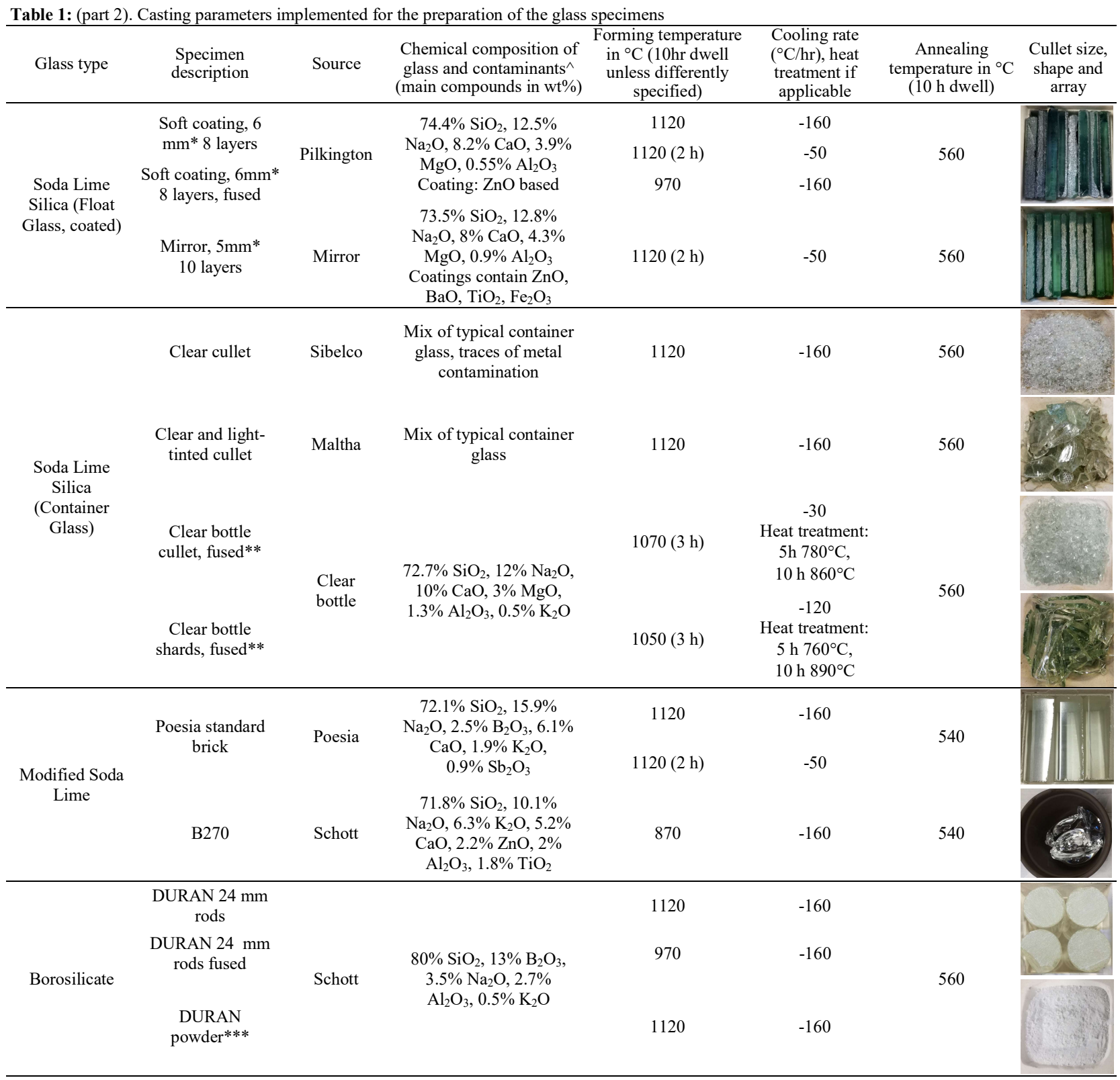

A Keyence VHX-7000 digital microscope with a 20-200x zoom lens is used to photograph defects on and in the cast samples. A selection of specimens is also inspected using an Ilis StrainScope Flex polariscope to determine potential residual stresses.

\section{Splitting Test Design and Experimental Set-Up}

A destructive splitting test is designed for the testing of $50 \mathrm{~mm}$ cubic cast glass specimens. The set-up comprises a High-Speed Steel 10\% Cobalt (HSS Co 10) toolbit of $25 \mathrm{~mm}$ square cross section, rotated by $45^{\circ}$ and positioned on a milled 52.4 hardened steel base, which

\footnotetext{
${ }^{3}$ A relatively low displacement rate is chosen to allow for possible
} crack arrests when singularities are encountered along the crack front is fixed on the base of a Zwick Z100 displacement controlled universal testing machine (Fig. 2). The cubic glass specimens are locally taped under the machine's steel head and centrally positioned above the toolbit edge. This edge, only slightly filleted to a radius of $233 \mu \mathrm{m}$, acts as a longitudinal sharp indenter on the bottom glass cube surface, as the machine head starts to move downwards with a $0.2 \mathrm{~mm} / \mathrm{min}$ rate $^{3}$, putting pressure to the bottom glass surface. With the increasing force, the indenter tip creates initial glass densification and crushing around it, accompanied by stable radial cracks, both at the direction of the force and perpendicular to it. 


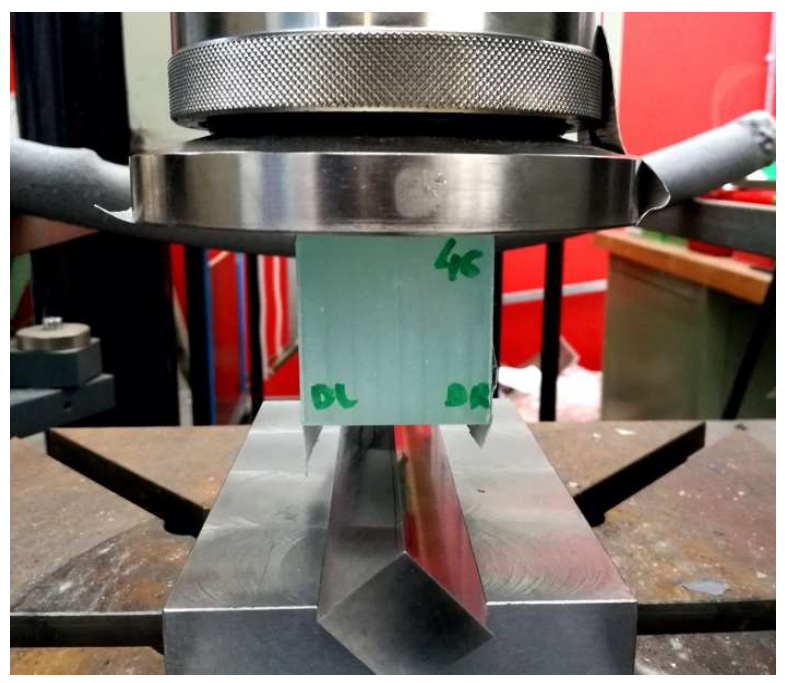

Fig. 2: Splitting test experimental set-up. The toolbit at the base acts as a longitudinal sharp indenter at the bottom surface of the glass specimen

When the force reaches a critical level, the glass cube is split in two pieces. The fractured surfaces are then studied with the Keyence VHX-7000 microscope. The splitting test provides quantitative information about the resistance of the tested glasses to deformation (hardness) and the resistance to fracture (toughness). Also qualitative information are extracted from the fracture analysis of the fractured surfaces regarding the role of inhomogeneities in the mesostructure to the glass network.

\section{Results}

\section{Cast Glass Specimens Evaluation}

The selected forming temperatures correspond to high glass viscosities, resulting to inhomogeneous glass specimens. The degree of inhomogeneity relates to the purity and shape of the cullet, in combination with the firing schedule (e.g., slow cooling, heat-treatment). Therefore, a variety of mesostructures are observed in the specimens, grouped in the following categories, as also seen in Fig. 3:

a. Fairly homogeneous: These specimens may contain miniscule air-bubbles. The lack of other defects and inhomogeneities results from the purity of the initial cullet, the high forming temperature and long dwell time used (e.g., at $1120^{\circ} \mathrm{C}$ for $10 \mathrm{~h}$ ) and the fast cooling scheme

b. Structured bubble veils: These concern parallel layers composed by multiple bubbles and occasionally cord, which are found within the glass specimen. Such layers are observed in coated float samples with a short dwell time at top temperature $(2 \mathrm{~h})$ that did not allow for the complete melting of the coating and its incorporation to the glass network (Fig. 4 right). The parallel appearance of these veils in the glass specimens is a result of the insertion of the cullet inside the mould in parallel orthogonal pieces

c. Random glassy/gaseous inhomogeneities: Such random structures may occur due to glass compositional variations in the cullet (e.g., Maltha clear glass consists of container glass produced by various manufacturers, Fig. 5 left) in combination to its random shape (e.g., shards). In addition, the slow pouring of the glass inside the mould (at high viscosity) can create swirling patterns of bubbles and cord which are reminiscent of the coiling of the glass pouring thread (Fig. 4 left)

d. Structured crystalline interlayers: These are thin crystallized layers within the glass network, situated at the contact surfaces of the cullet pieces (Fig. 6 right). They are formed during fusing at low temperatures (e.g., $970^{\circ} \mathrm{C}$ ) and prolonged dwell times (e.g., $10 \mathrm{~h}$ ) at a temperature range that promotes crystallization. The crystalline types identified by X-Ray Fluorescent (XRD) analyses are wollastonite $2 \mathrm{M}, \beta$-cristobalite and devitrite for the Float $970^{\circ} \mathrm{C}$ glass and $\beta$-cristobalite for the Borosilicate $970^{\circ} \mathrm{C}$ glass (Bristogianni et al., 2020). The structured geometry is linked to the defined shape of the original cullet

e. Random crystalline elements: These consist of acicular or linear crystalline formations of larger thickness than in the category above. These crystals form due to the kiln-casting of the specimens at temperatures below the liquidus point and the heattreatment at the crystallization peak zone thereafter. XRD analyses characterize these crystals as Wollastonite-2M and $\alpha$-cristobalite (Lei, 2019, 
Fig. 6 left) in the case of container glass. The shape of these crystals is directly linked to the initial cullet shape (round cullet leads to singular acicular formations while shards lead to the grouping of the crystals into linear arrangements)

f. Fused, porous: The specimens are produced by the sintering of powdered cullet at relatively low

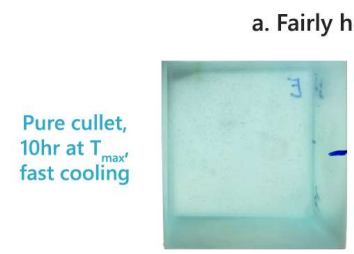

FT Float $1120^{\circ} \mathrm{C}$

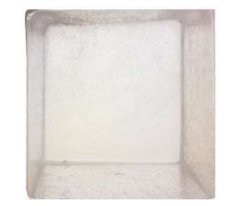

Poesia $1120^{\circ} \mathrm{C}$ b. Structured bubble veils

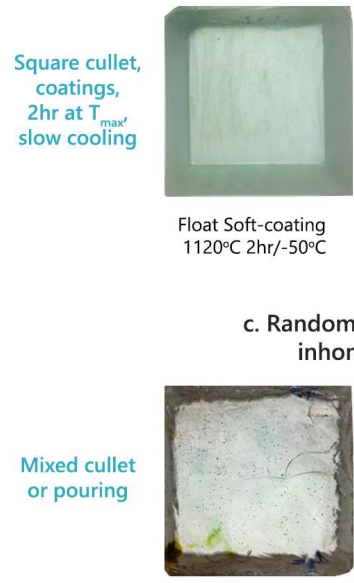

Maltha clear $1120^{\circ} \mathrm{C}$

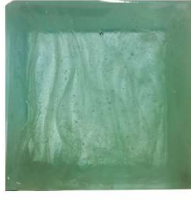

Float Mirror-coating $1120^{\circ} \mathrm{C} 2 \mathrm{hr} /-50^{\circ} \mathrm{C}$

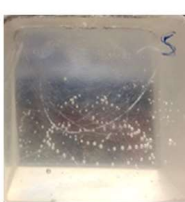

B270 flowerpot $870^{\circ} \mathrm{C}$

temperatures (e.g., $970^{\circ} \mathrm{C}$ for soda lime glass) which may coincide with the peak-crystallization temperature range (Anagni et al., 2020). A crystallized, porous structure is therefore achieved. At higher temperatures (e.g., $1120^{\circ} \mathrm{C}$ ), a glassy porous structure is obtained (Fig. 5 right)

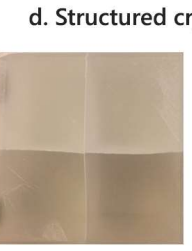

Borosilicate $970^{\circ} \mathrm{C}$

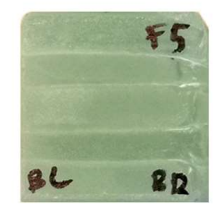

$10 \mathrm{~mm}$ Float $970^{\circ} \mathrm{C}$

Round/square

cullet, shape

Fusion/ low $\mathrm{T}_{\text {max }}$

e. Random crystalline elements

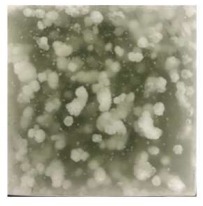

Clear bottle cullet $1070 / 780 / 860^{\circ} \mathrm{C}$,

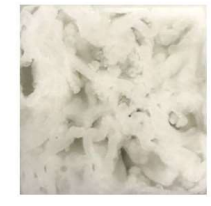

Clear bottle shards
Cullet or shards, $3 \mathrm{hr}$ at $\mathrm{T}_{\text {max }}$ heat treatment f. Fused, porous

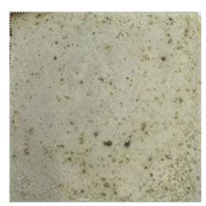
Low-iron Float
powder, $970^{\circ} \mathrm{C}$

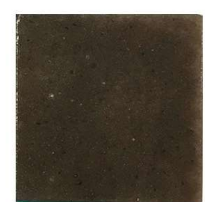

Borosilicate

Fig. 3: Categories of encountered mesostructures, as a result of the casting parameters followed. The defects creating these mesostructures are crystalline formations, glassy inhomogeneities or gaseous inclusions, either acting alone or in combination
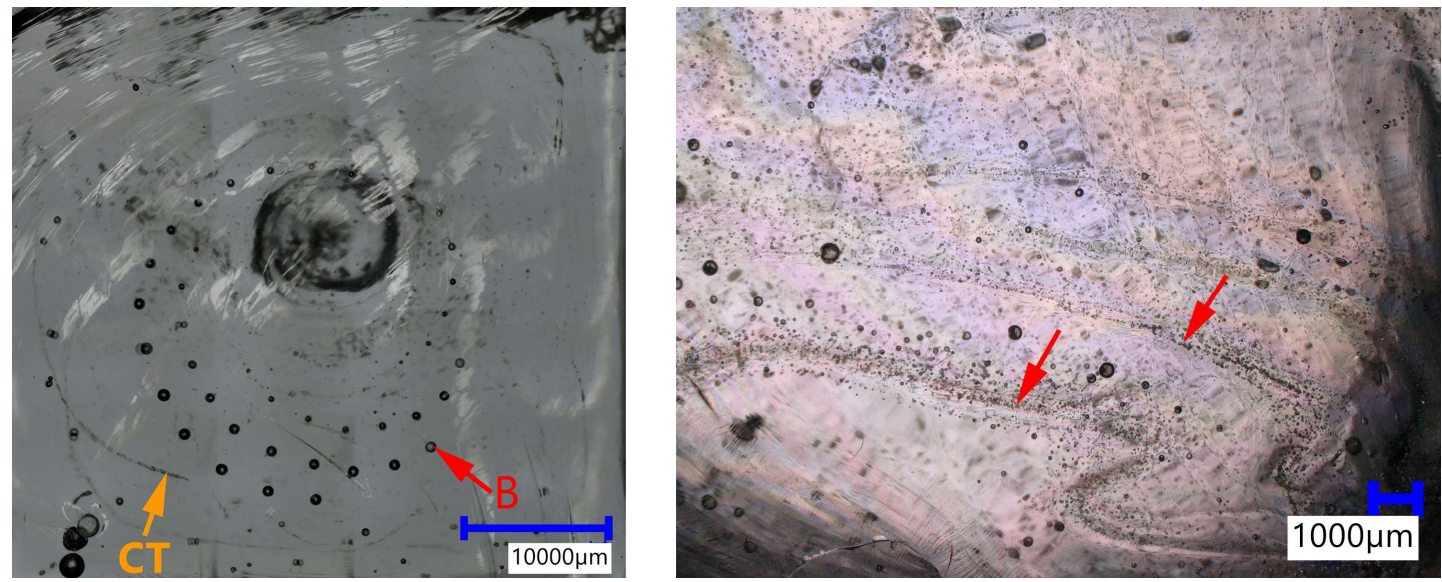

Fig. 4: Bubble formation ("B"), cord and Crystalline Traces ("CT") in a spiral arrangement in a "B270 $870^{\circ} \mathrm{C}$ " specimen (left); a reminisce of the coiling of the molten glass as it was slowly poured inside the mould from the flowerpot. Parallel bubble veils in a "Mirror $1120^{\circ} \mathrm{C},-50^{\circ} \mathrm{C} / \mathrm{hr}$ specimen (right). The presence of the specific hard-to-melt metallic coating in combination with the shorter dwell time ( $2 \mathrm{~h}$ instead of $10 \mathrm{~h}$ ) at top temperature, results in bubble veils at the fusion area between the glass pieces 

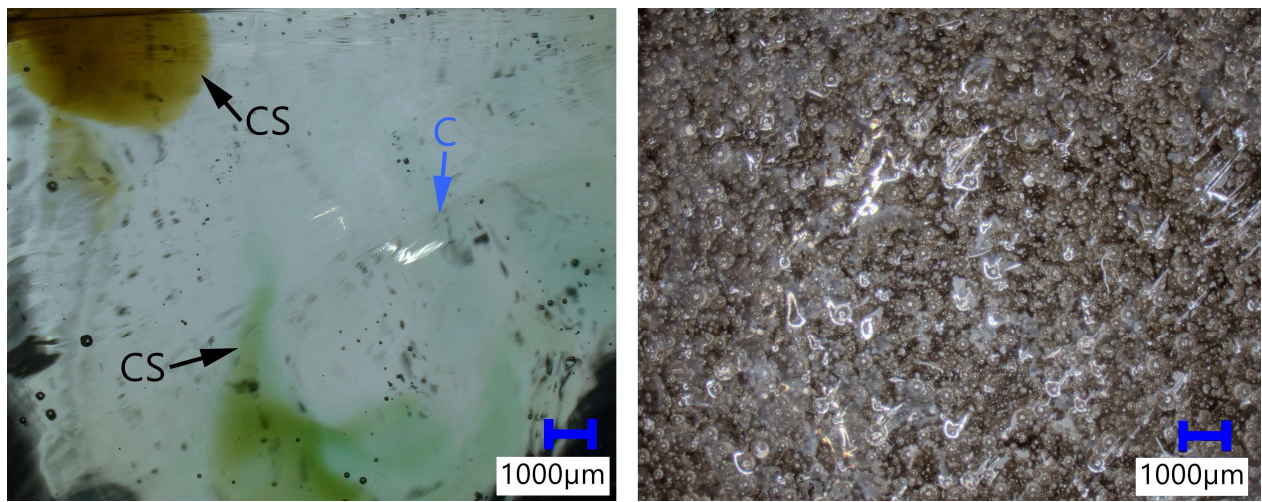

Fig. 5: Glassy inhomogeneities in the form of transparent Cord ("C") and Colour Streak ("CS") in a "Maltha Clear $1120^{\circ} \mathrm{C}$ bottle"

(left) and high population of bubbles in a "Borosilicate powder $1120^{\circ} \mathrm{C}$ " specimen (right)
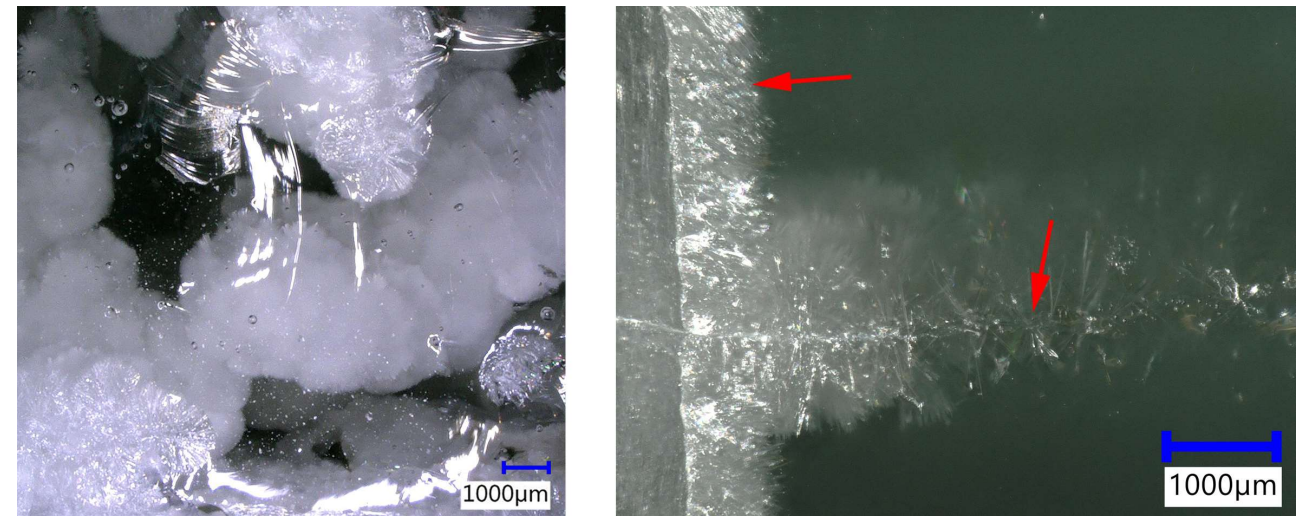

Fig. 6: Crystalline inhomogeneities encountered in a heat-treated "Clear bottle cullet $1070^{\circ} \mathrm{C}$ " specimen (left) and a fused "Soft Coated float $970^{\circ} \mathrm{C}$ " specimen (right). The forming or heat-treating of these soda lime silica glasses below the liquidus point and at temperatures that favour crystallization, is responsible for the encountered crystalline inclusions

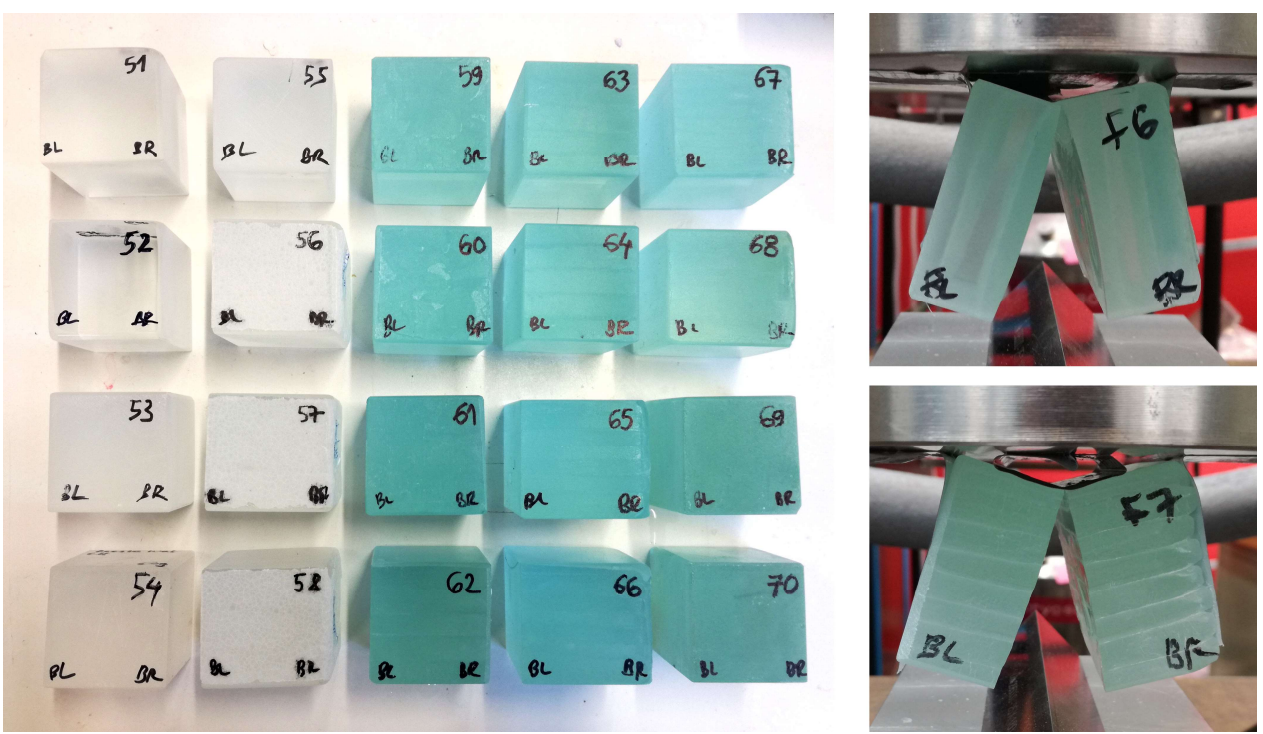

Fig. 7: Cast Poesia and Float glass cubic specimens (left) and orientation of the crystalline interlayer mesostructure of two fused float specimens to the direction of the force (right). Only the bottom and top surface of the specimens are polished up to 600 grit, while the side surfaces are left unprocessed 


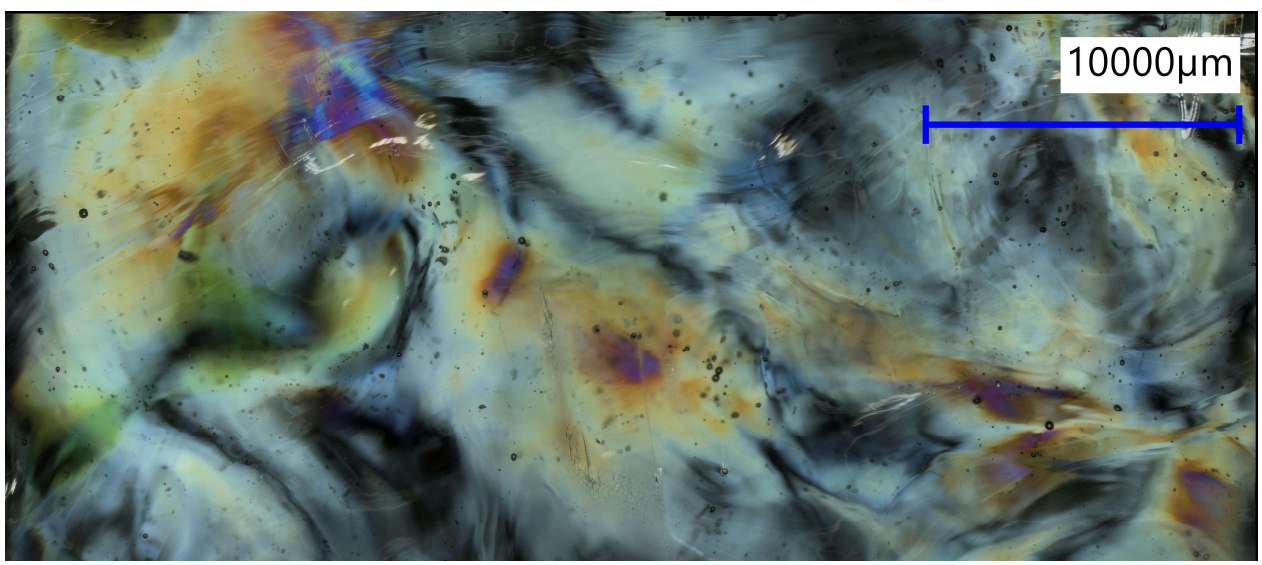

Fig. 8: "Maltha Clear $1120^{\circ} \mathrm{C}$ bottle" specimen, as seen through crossed-polarized light. The localized stress zones are the result of compositional variations in the initial cullet shards

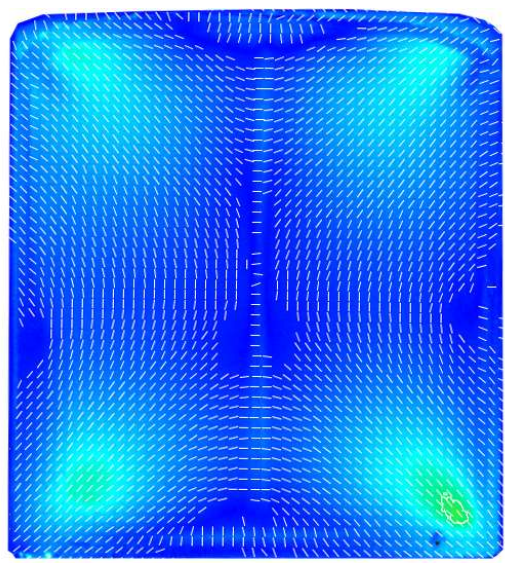

Boro $\Phi 24 \mathrm{~mm}$ rods $1120^{\circ} \mathrm{C}$ $67 \mathrm{~nm}$

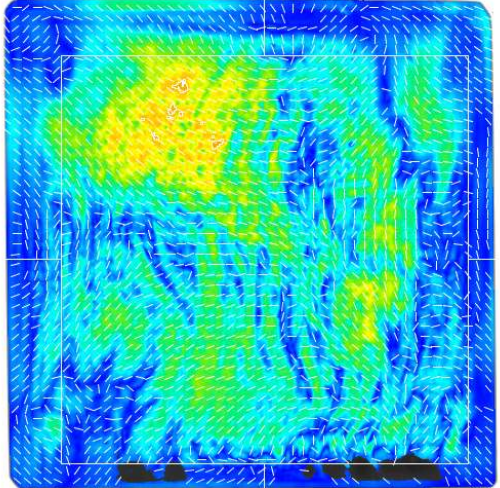

Float, mirrors $1120^{\circ} \mathrm{C}$ $113 \mathrm{~nm}$

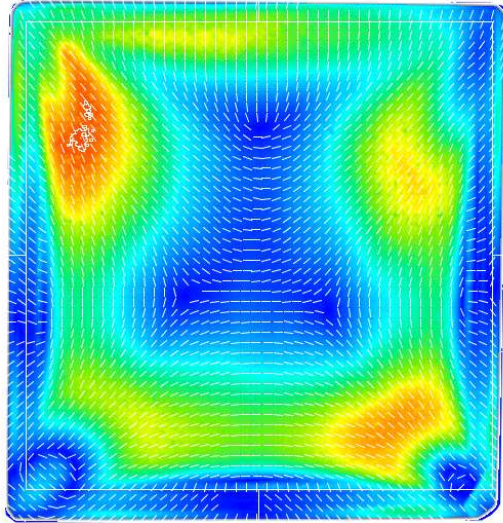

FT Float $1120^{\circ} \mathrm{C}$

$132 \mathrm{~nm}$

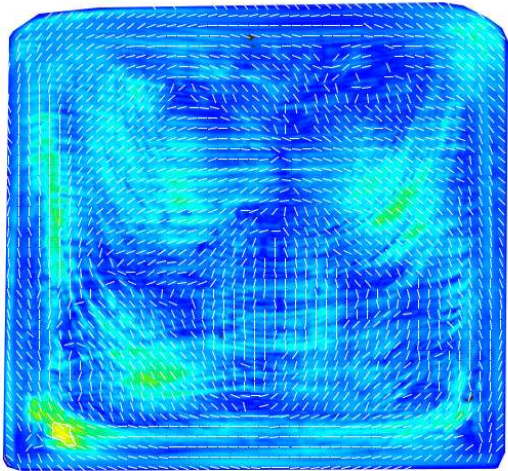

$\mathrm{B} 270870^{\circ} \mathrm{C}$

$85 \mathrm{~nm}$

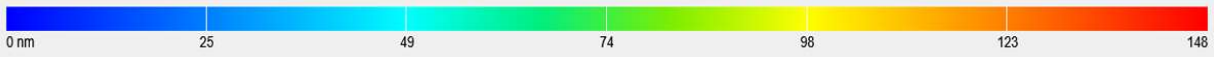

Fig. 9: Internal stresses in a selection of cast glass specimens, as captured with an Ilis polariscope. The colour gradient refers to the relative phase retardation between the two component waves of the polarized light 
In cases where the geometry of the mesostructure is prominent, such as in categories $b$ and $d$, then the orientation of the interfaces -either in the form of bubble veils or crystalline layers- in relation to the toolbit and force direction is marked during testing. In this manner, the effect of such interlayers to the structural performance of the glass cubes can be studied (Fig. 7).

The above described inhomogeneities become prominent once the specimens are observed through cross-polarized light (Fig. 8). The optical path traveling through the glass matrix will propagate at a different speed when encountering a compositional variation or a zone experiencing mechanical stress. The optical retardation (optical path difference) due to these inhomogeneities is measured via an Ilis StrainScope Flex circular polariscope (Fig. 9). Subtle bubble veils such as in the case of the pure Borosilicate $1120^{\circ} \mathrm{C}$ or the spiral coiling structure of the B270 samples, barely cause any optical retardation, whereas the bubble veils created from non-incorporated coatings (e.g., mirrors) will have a more significant impact to the direction of the light path. Nonetheless, higher optical retardation was occasionally observed in pure specimens such as the FT Float $1120^{\circ} \mathrm{C}$ or Poesia $1120^{\circ} \mathrm{C}$ than in the inhomogeneous ones (Fig. 9). These zones are located at the corners of the cubes, where -due to the shape of the glass- tensile stresses are more likely to appear during cooling. This suggests that incomplete relief of the internal stresses due to random alterations to the thermal history (e.g., location of the specimen in the kiln may affect its thermal profile) may be more significant than the stresses induced by glassy or gaseous inhomogeneities.

Apart from the observed inhomogeneities originating by the followed casting process, the specimens may also bare surface flaws due to machining and handling damage (Fig. 10). These are mainly striations, small inclusions caused by mould contamination and chipping.

\section{Splitting Tests}

Figure 11, 12 and Table 2 show the force at failure of the $50 \mathrm{~mm}$ cubic specimens subjected to the splitting test. From the 64 tested specimens, 33 had established full contact with the toolbit and thus an even distribution of the force. These results are considered accurate for evaluating the force in relation to the glass composition and mesostructure characteristics. They also allow a reliable correlation between the force and the extent of lateral damage at the bottom surface. The rest of the specimens tilted during the building up of the force while testing, having as a result an uneven stress distribution along the toolbit that exposed one side of the cube to a maximum stress while the opposite side was not in contact with the toolbit. This would lead to an obvious failure of the specimens at lower force values. Nonetheless, seven from these specimens, making at least $85 \%$ contact with the toolbit, where used together with the $100 \%$ contact specimens for calculating the average force per glass type. This distribution (Fig. 12), although depicting lower force values, still serves as a good comparison between the glass types. Specimens with less than $85 \%$ contact were discarded as inaccurate.

Relative to the fully supported specimens (Fig. 11), the data for each glass type is consistent within a range of 5 $\mathrm{kN}$. The highest force values are seen in the homogeneous $\left(1120^{\circ} \mathrm{C}\right)$ and the fused $\left(970^{\circ} \mathrm{C}\right)$ borosilicate specimens (42 and $38.6 \mathrm{kN}$ respectively), followed by the FT Float $(36.5 \mathrm{kN})$, Float $(32.9 \mathrm{kN})$ and Soft-coating $(33.9 \mathrm{kN})$ samples produced at high temperature and quenched either at a -160 or $-50^{\circ} \mathrm{C} / \mathrm{hr}$ rate. The fused variants of these SLS glasses resist much lower forces (in average 16.9-19.3 kN), presenting similar results regardless of the orientation of the crystallized interfaces. Significant differences are found in the Poesia glasses (12-28.9 kN), in regard to the firing schedule (fast vs. slow cooling, kilncast vs. hot poured) and the finishing surface (glossy vs. mat). The samples produced by powdered glass (porous and crystallized) are significantly weaker (as low as 11.1 $\mathrm{kN}$ ) from the homogeneous or even fused variants of the same glass composition.

Container glass specimens, either homogeneous or with crystalline inclusions, are found weaker (21.8-24.6 $\mathrm{kN}$ in average) than the homogeneous float glass variants. The obtained data is nonetheless only an indication of the fracture resistance of the different glasses and due to the limited number of test repetition, they cannot be statistically conclusive.

The reference adhesively bonded float glass specimens have almost identical results regardless of the orientation of the float glass plies $(18.7-20.9 \mathrm{kN})$ and are comparable to the fused float samples, but $40 \%$ less resistant than the homogeneous kiln-cast float samples $\left(1120^{\circ} \mathrm{C},-50^{\circ} \mathrm{C} / \mathrm{hr}\right)$.

\section{Fracture analysis}

A repeating fracture pattern is found among the majority of the tested samples. Looking at the crack-front surface, an initial, crushed zone of maximum $500 \mu \mathrm{m}$ thickness appears along the area directly exposed to the sharp toolbit (Fig. 13-14). This zone is followed by a second zone that involves the formation of stable medianradial cracks of maximum $4000 \mu \mathrm{m}$ radius. The extent of the crushed zone and radius of the stable cracks is linked to the applied force. 


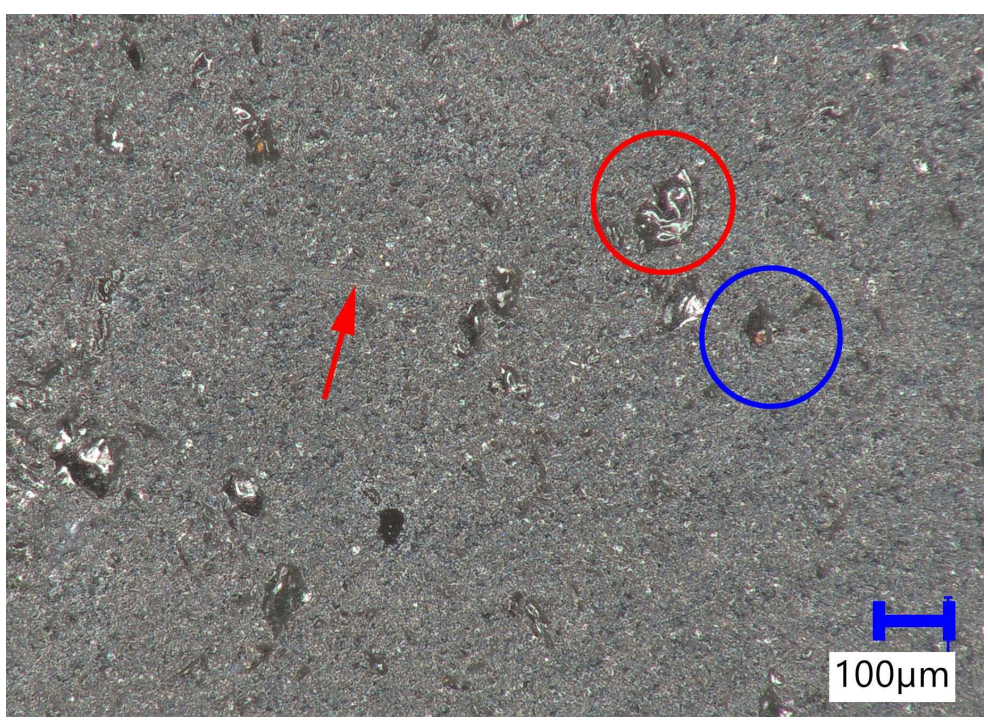

Fig. 10: Bottom surface of an "FT Float $1120^{\circ} \mathrm{C}$ " specimen that has been ground and polished up to a 600 grit. Common defects include striations (arrow) and chipping (red circle) caused during grinding and inclusions originating from mould contact (blue circle)
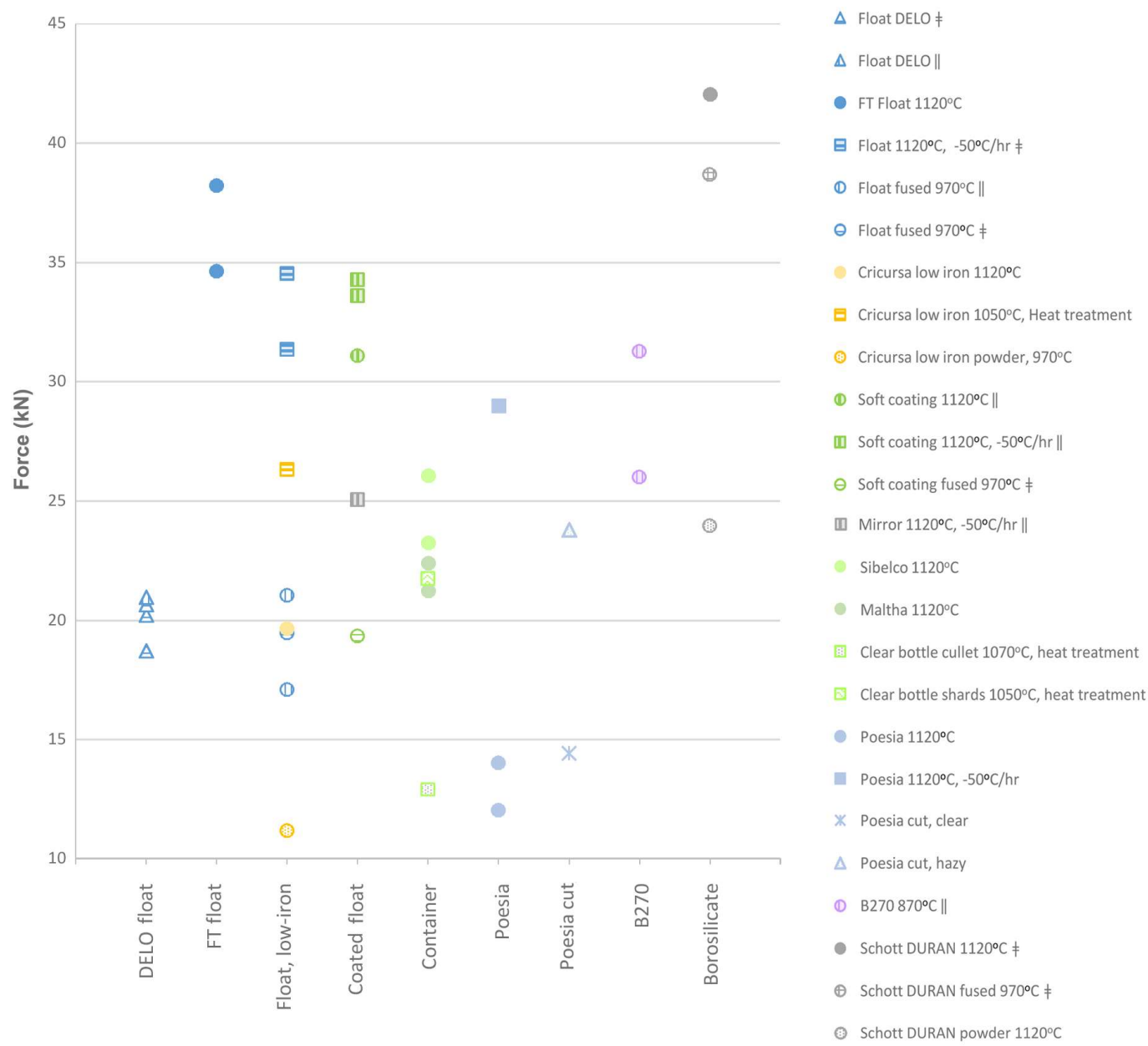

Fig. 11: Force at failure, as reported during the splitting test. Only fully supported specimens are included in the graph 


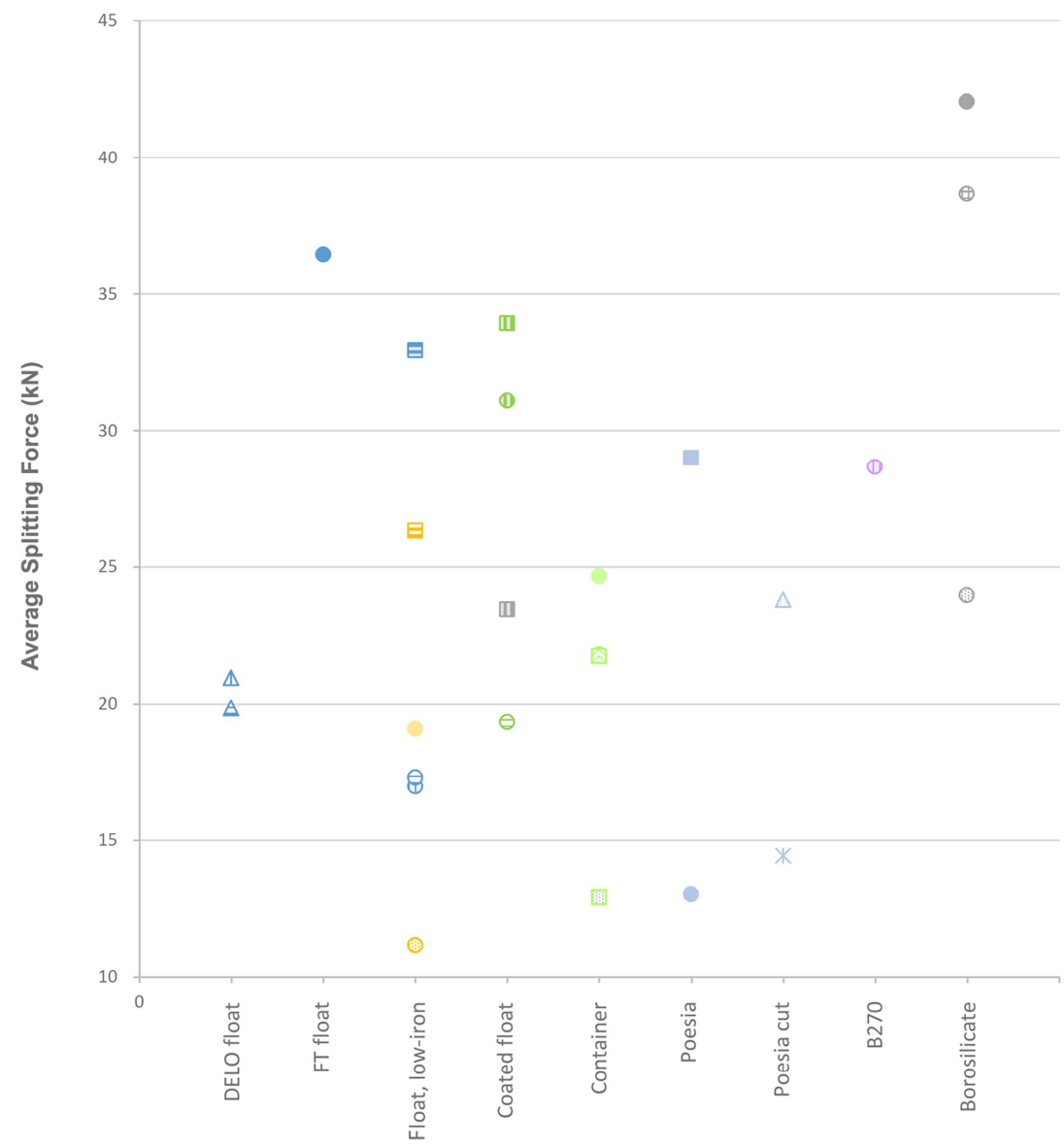

\begin{tabular}{|c|c|c|c|c|c|}
\hline$\Delta$ & Float DELO \# & (1) & Soft coating $1120^{\circ} \mathrm{C} \|$ & - & Poesia $1120^{\circ} \mathrm{C}$ \\
\hline$\Delta$ & Float DELO \| & 四 & Soft coating $1120^{\circ} \mathrm{C},-50^{\circ} \mathrm{C} / \mathrm{hr} \|$ & 口 & Poesia $1120^{\circ} \mathrm{C},-50^{\circ} \mathrm{C} / \mathrm{hr}$ \\
\hline - & FT Float $1120^{\circ} \mathrm{C}$ & $\theta$ & Soft coating fused $970^{\circ} \mathrm{C} \neq$ & * & Poesia cut, clear \\
\hline$\exists$ & Float $1120^{\circ} \mathrm{C},-50^{\circ} \mathrm{C} / \mathrm{hr} \neq$ & 四 & Mirror $1120^{\circ} \mathrm{C},-50^{\circ} \mathrm{C} / \mathrm{hr} \|$ & $\Delta$ & Poesia cut, hazy \\
\hline D & Float fused $970^{\circ} \mathrm{C} \|$ & P & Sibelco $1120^{\circ} \mathrm{C}$ & (1) & $\mathrm{B} 270870^{\circ} \mathrm{C} \|$ \\
\hline$\theta$ & Float fused $970^{\circ} \mathrm{C} \neq$ & - & Maltha $1120^{\circ} \mathrm{C}$ & • & Schott DURAN $1120^{\circ} \mathrm{C} \neq$ \\
\hline 0 & Cricursa low iron $1120^{\circ} \mathrm{C}$ & 영 & Clear bottle cullet $1070^{\circ} \mathrm{C}$, heat treatment & $\oplus$ & Schott DURAN fused $970^{\circ} \mathrm{C} \neq$ \\
\hline 日 & Cricursa low iron $1050^{\circ} \mathrm{C}$, Heat treatment & Q & Clear bottle shards $1050^{\circ} \mathrm{C}$, heat treatment & ()ㅜㅇ & Schott DURAN powder $1120^{\circ} \mathrm{C}$ \\
\hline
\end{tabular}

Fig. 12: Average force at failure of glass specimens establishing $85-100 \%$ contact with the toolbit

Building upon the created damage by the sharp indenter tip, unstable crack propagation will start once the critical fracture toughness is reached, at 1 or 2 damaged points simultaneously. The crack origin is not associated with a specific inherent material flaw, but with the stress intensity and the damage caused by the toolbit, which is overruling the presence of any other defect. The fracture origin is usually located close to one of the cube sides, possibly due to minor tilting of the specimen during testing. From the origin site and following the direction of crack propagation, secondary Wallner lines start, created from the interaction with singularities at the cube's bottom and side surfaces (Fig. 15 and 16). The Wallner lines reveal the direction of crack propagation (dcp) in each specimen. Intense shear hackle lines appear around the fracture origin, while they are also present at secondary damage sites to a smaller extent (Fig. 15). 
Telesilla Bristogianni et al. / International Journal of Structural Glass and Advanced Materials Research 2021, Volume 5: 195.225 DOI: $10.3844 /$ sgamrsp.2021.195.225

\begin{tabular}{|c|c|c|c|c|c|c|c|c|c|}
\hline \multirow{3}{*}{ Glass type } & \multirow{3}{*}{$\begin{array}{l}\text { Specimen } \\
\text { description }\end{array}$} & \multirow{3}{*}{ Source } & \multirow{3}{*}{$\begin{array}{l}\text { Forming } \\
\text { temperature in } \\
{ }^{\circ} \mathrm{C}(10 \mathrm{~h} \text { dwell } \\
\text { unless } \\
\text { differently } \\
\text { specified })\end{array}$} & \multirow{3}{*}{$\begin{array}{l}\text { Cooling rate } \\
\left({ }^{\circ} \mathrm{C} / \mathrm{hr}\right) \text {, heat } \\
\text { treatment if } \\
\text { applicable }\end{array}$} & \multirow{3}{*}{$\begin{array}{l}\text { Mesostructure } \\
\text { orientation in } \\
\text { respect to the } \\
\text { force direction (if } \\
\text { applicable) }\end{array}$} & \multirow{2}{*}{$\begin{array}{l}\text { Number of valid } \\
\text { specimens }\end{array}$} & \multicolumn{3}{|c|}{ Splitting force $(\mathrm{kN})$} \\
\hline & & & & & & & Minimum & Maximum & Average \\
\hline & & & & & & $\begin{array}{l}85-100 \% \\
\text { support }\end{array}$ & $\begin{array}{l}85-100 \% \\
\text { support }\end{array}$ & $\begin{array}{l}100 \% \\
\text { support }\end{array}$ & $\begin{array}{l}85-100 \% \\
\text { support }\end{array}$ \\
\hline \multirow{2}{*}{$\begin{array}{l}\text { Soda Lime } \\
\text { Silica } \\
\text { glass), gloat }\end{array}$} & \multirow{2}{*}{$\begin{array}{lr}\text { Float } & \text { Delo } \\
4468, & 10 \mathrm{~mm}^{*} 5 \\
\text { layers }\end{array}$} & \multirow{2}{*}{ IFS-SGT } & \multirow{2}{*}{\multicolumn{2}{|c|}{ Industrially produced }} & $\begin{array}{l}\text { Adhesive } \\
\text { interlayers } \\
\text { perpendicular to } F\end{array}$ & 3 & 18.72 & 20.64 & 19.86 \\
\hline & & & & & $\begin{array}{l}\text { Adhesive } \\
\text { interlayers } \\
\text { parallel to F }\end{array}$ & 1 & - & 20.96 & - \\
\hline \multirow{6}{*}{$\begin{array}{lr}\text { Soda } & \text { Lime } \\
\text { Silica } & \text { (Float } \\
\text { Glass) } & \end{array}$} & FT float ${ }^{\wedge}$ & \multirow[b]{3}{*}{ IFS-SGT } & 1120 & -160 & - & 2 & 34.63 & 38.22 & 36.42 \\
\hline & $\begin{array}{l}\text { Float } 10 \mathrm{~mm} * 5 \\
\text { layers }\end{array}$ & & $1120(2 \mathrm{~h})$ & -50 & $\begin{array}{l}\text { Subtle bubble } \\
\text { veils } \\
\text { perpendicular to } F\end{array}$ & 2 & 31.34 & 34.51 & 32.93 \\
\hline & $\begin{array}{l}\text { Float } 10 \mathrm{~mm}^{*} 5 \\
\text { layers, fused }\end{array}$ & & 970 & -160 & $\begin{array}{l}\text { Crystalline } \\
\text { interfaces parallel } \\
\text { to F } \\
\text { Crystalline } \\
\text { interfaces } \\
\text { perpendicular to F }\end{array}$ & 3 & 15.07 & 19.46 & 17.27 \\
\hline & Low-iron float & \multirow{3}{*}{ Cricursa } & 1120 & -160 & - & 2 & 18.53 & 19.65 & 19.09 \\
\hline & $\begin{array}{l}\text { Low-iron float, } \\
\text { heat-treated** }\end{array}$ & & $1050(3 \mathrm{~h})$ & -30 Heat treat. & - & 1 & - & 26.32 & - \\
\hline & $\begin{array}{l}\text { Low-iron float } \\
\text { powdered, } \\
\text { fused*** }\end{array}$ & & 970 & -160 & - & 1 & - & 11.15 & - \\
\hline \multirow{4}{*}{$\begin{array}{l}\text { Soda Lime } \\
\text { Silica } \\
\text { Glass, } \\
\text { coated) }\end{array}$} & Soft coating, & \multirow{4}{*}{ Pilkington } & 1120 & -160 & $\begin{array}{l}\text { Subtle bubble } \\
\text { veils parallel to F }\end{array}$ & 1 & - & 31.09 & - \\
\hline & $6 \mathrm{~mm} * 8$ layers & & $1120(2 \mathrm{~h})$ & -50 & $\begin{array}{l}\text { Bubble veils } \\
\text { parallel to F }\end{array}$ & 2 & 33.59 & 34.27 & 33.93 \\
\hline & $\begin{array}{l}\text { Soft coating, } 6 \\
\mathrm{~mm} * 8 \text { layers, } \\
\text { fused }\end{array}$ & & 970 & -160 & $\begin{array}{l}\text { Crystalline } \\
\text { interfaces } \\
\text { perpendicular to } F\end{array}$ & 1 & - & 19.33 & - \\
\hline & $\begin{array}{l}\text { Mirror, 5mm* } \\
10 \text { layers }\end{array}$ & & $1120(2 \mathrm{~h})$ & -50 & $\begin{array}{l}\text { Prominent bubble } \\
\text { veils parallel to } F\end{array}$ & 2 & 21.84 & 25.04 & 23.44 \\
\hline \multirow{4}{*}{$\begin{array}{l}\text { Soda Lime } \\
\text { Silica } \\
\text { (Container } \\
\text { Glass) }\end{array}$} & Clear cullet & Sibelco & 1120 & -160 & - & 2 & 23.25 & 26.06 & 24.66 \\
\hline & $\begin{array}{l}\text { Clear and light- } \\
\text { tinted cullet }\end{array}$ & Maltha & 1120 & -160 & - & 2 & 21.22 & 22.39 & 21.80 \\
\hline & $\begin{array}{l}\text { Clear bottle } \\
\text { cullet, fused** }\end{array}$ & \multirow{2}{*}{$\begin{array}{l}\text { Clear } \\
\text { bottle }\end{array}$} & $1070(3 \mathrm{~h})$ & -30 Heat treat. & - & 1 & - & 12.89 & - \\
\hline & $\begin{array}{l}\text { Clear bottle } \\
\text { shards, fused** }\end{array}$ & & $1050(3 \mathrm{~h})$ & $\begin{array}{l}-120 \quad \text { Heat } \\
\text { treat. }\end{array}$ & - & 1 & - & 21.74 & - \\
\hline \multirow{5}{*}{$\begin{array}{l}\text { Modified } \\
\text { Soda Lime }\end{array}$} & \multirow{4}{*}{$\begin{array}{l}\text { Poesia standard } \\
\text { brick }\end{array}$} & \multirow{4}{*}{ Poesia } & 1120 & -160 & - & 3 & 12.00 & 14.02 & 13.00 \\
\hline & & & $1120(2 \mathrm{~h})$ & -50 & - & 1 & - & 28.98 & - \\
\hline & & & \multicolumn{2}{|c|}{ Industrially produced (clear) } & - & 1 & - & 14.42 & - \\
\hline & & & \multicolumn{2}{|c|}{ Industrially produced (hazy) } & - & 1 & - & 23.79 & - \\
\hline & B270 & Schott & 870 & -160 & $\begin{array}{l}\text { Coiling bubble } \\
\text { veils parallel to F }\end{array}$ & 2 & 26.01 & 31.28 & 28.64 \\
\hline \multirow{3}{*}{ Borosilicate } & $\begin{array}{l}\text { DURAN } 24 \mathrm{~mm} \\
\text { rods }\end{array}$ & \multirow{3}{*}{ Schott } & 1120 & -160 & $\begin{array}{l}2 \text { Crossed subtle } \\
\text { bubble veils, } \\
\text { perpendicular to F }\end{array}$ & 1 & - & 42.04 & - \\
\hline & $\begin{array}{l}\text { DURAN } 24 \mathrm{~mm} \\
\text { rods fused }\end{array}$ & & 970 & -160 & $\begin{array}{l}2 \text { Crossed } \\
\text { crystalline } \\
\text { interfaces, } \\
\text { perpendicular to F }\end{array}$ & 1 & - & 38.66 & - \\
\hline & $\begin{array}{l}\text { DURAN } \\
\text { powder*** }\end{array}$ & & 1120 & -160 & - & 1 & - & 23.97 & - \\
\hline
\end{tabular}

${ }^{\wedge}$ The labelling "FT Float" refers to the use of Fully Tempered float glass shards as cullet. The final kiln-cast components are annealed and the thermal history of the shards is erased ** Sample prepared by Shan Cindy Lei (2019) as part of her MSc work

*** Sample prepared by Guilia Maria Anagni, as part of her MSc work (Anagni et al., 2020)

The fracture origin is in most cases mist-free, which according to Gopalakrishnan and Mecholsky (2014) is characteristic for mixed loading conditions (mode I: Tension, combined with mode II: Shear). Arrest lines often accompanied by perpendicular shear marks. The intensity in the morphology of the Wallner lines is proportional to the amount of stored elastic strain energy prior to cracking (Fig. 16).
The crack front will interact with singularities in the mesostructure of the kiln-cast specimens in the form of wing gulls, arrest lines, or shear hackle lines (Fig. 17-19). However, a significant crack path deviation due to the presence of a zone of gaseous or glassy inhomogeneity in the glass- for example a bubble veil or extended cord close to and parallel to the crack frontis not observed. 


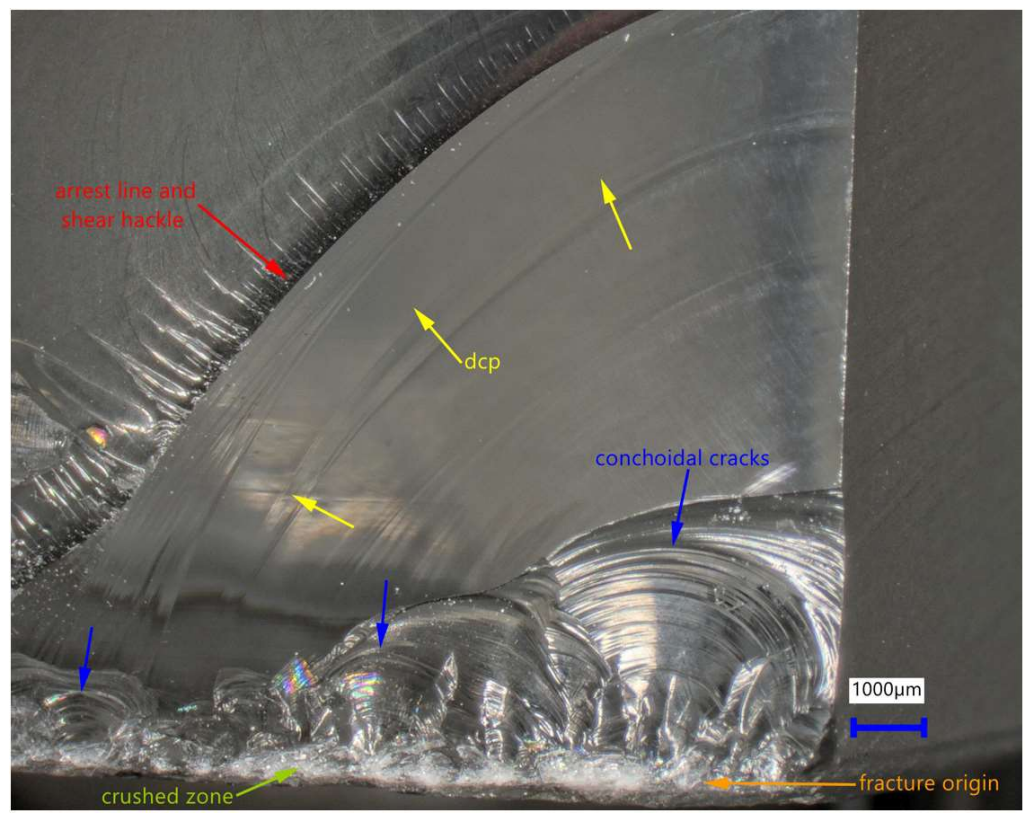

Fig. 13: Crack front showing the fracture origin in a "Poesia cut, clear" specimen, the crushed zone in contact with the toolbit, the formation of multiple conchoidal cracks, the direction of crack propagation (dcp) and the momentary arrest of the crack
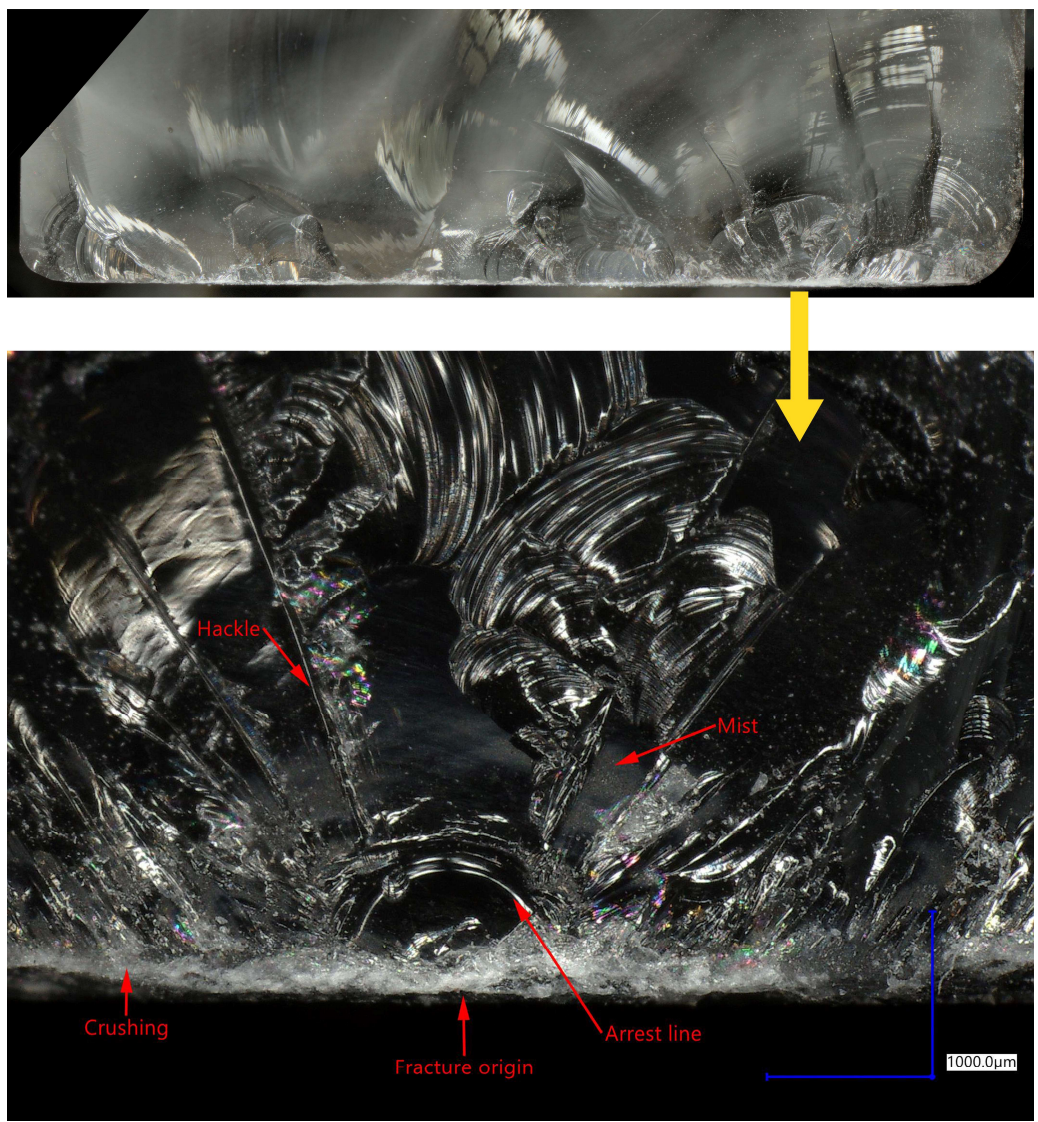

Fig. 14: Crack front in a "Poesia cut, clear" specimen. The fracture origin is located at the position with the most prominent hackle lines. The arrest line at the fracture origin site could suggest a slow crack growth. In addition, this is one of the very few specimens in this study that showed mist around the fracture origin 
Telesilla Bristogianni et al. / International Journal of Structural Glass and Advanced Materials Research 2021, Volume 5: 195.225 DOI: $10.3844 /$ sgamrsp.2021.195.225
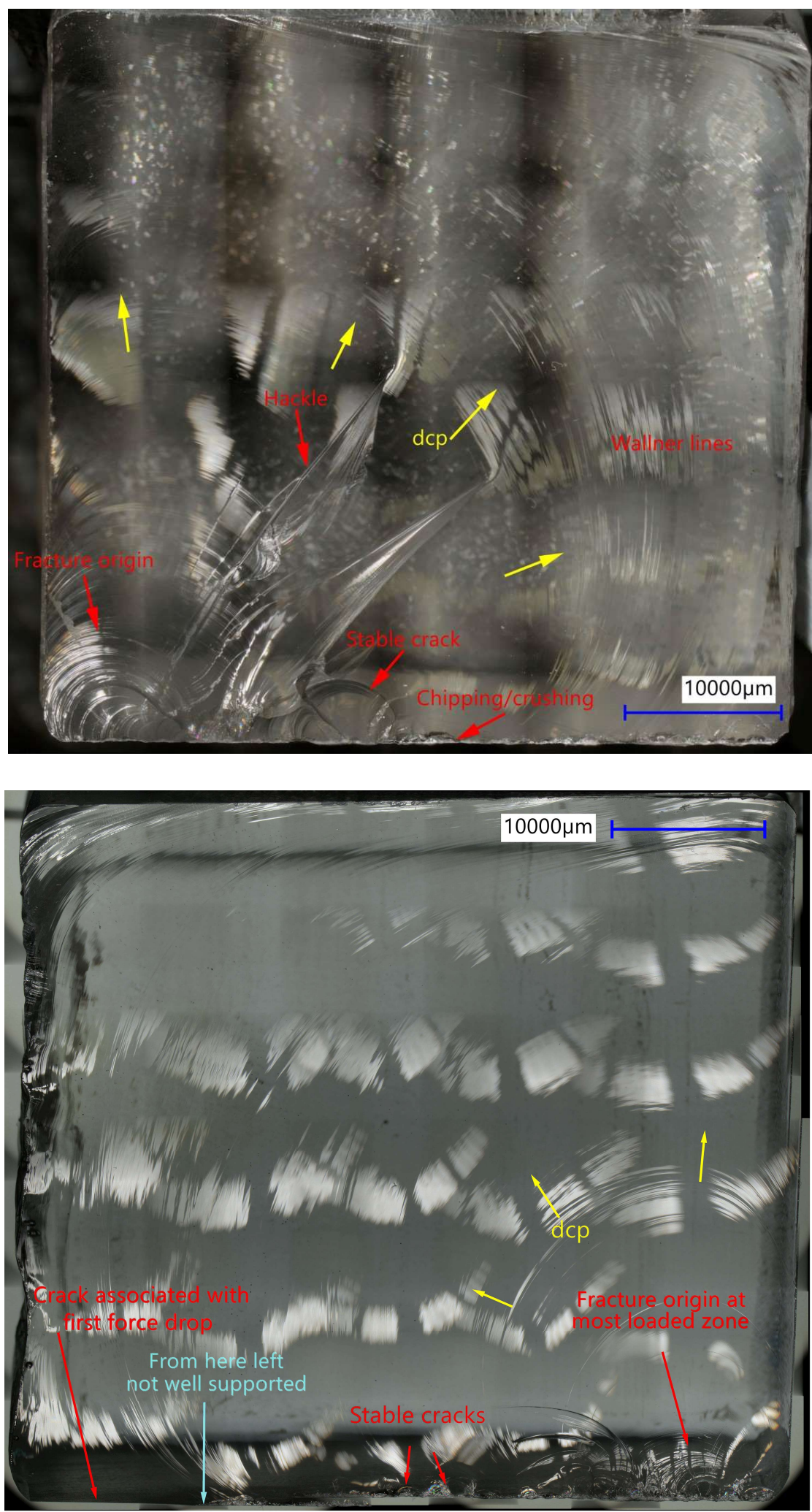

Fig. 15: Crack front surface of a fully supported "Poesia $1120^{\circ} \mathrm{C}$ " specimen that failed at $14 \mathrm{kN}$ (top) and a partially supported "Cricursa Low-iron Float $1120^{\circ} \mathrm{C}$ " specimen that failed at $13.5 \mathrm{kN}$ (bottom). The Wallner lines show the direction of crack propagation 
Telesilla Bristogianni et al. / International Journal of Structural Glass and Advanced Materials Research 2021, Volume 5: 195.225 DOI: $10.3844 /$ sgamrsp.2021.195.225
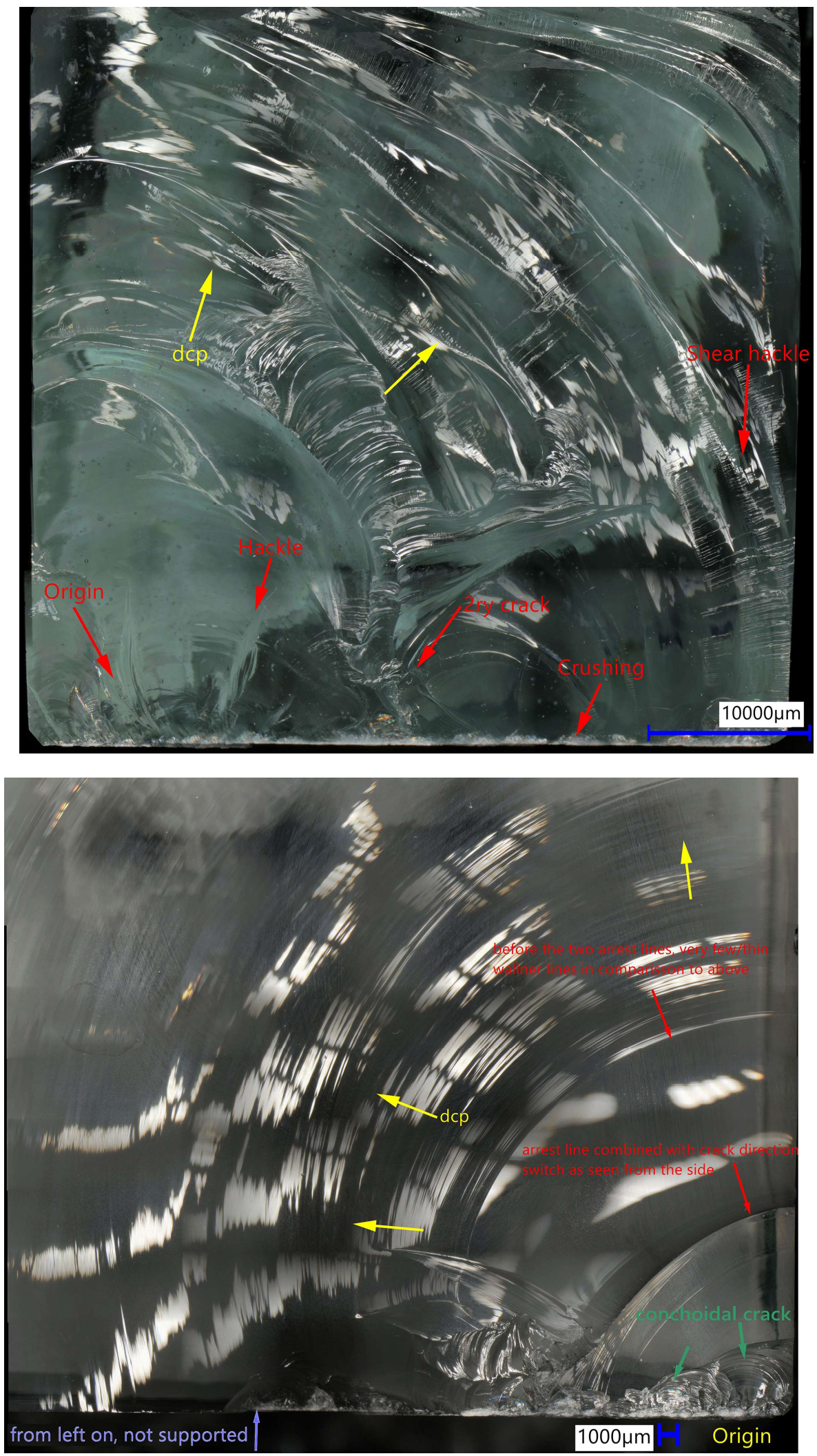

Fig. 16: Crack front surface of a fully supported "FT Float $1120^{\circ} \mathrm{C}$ " specimen that failed at $38.2 \mathrm{kN}$ (top) and a partially supported "Poesia cut, clear" specimen that failed at $5.8 \mathrm{kN}$ (bottom) 


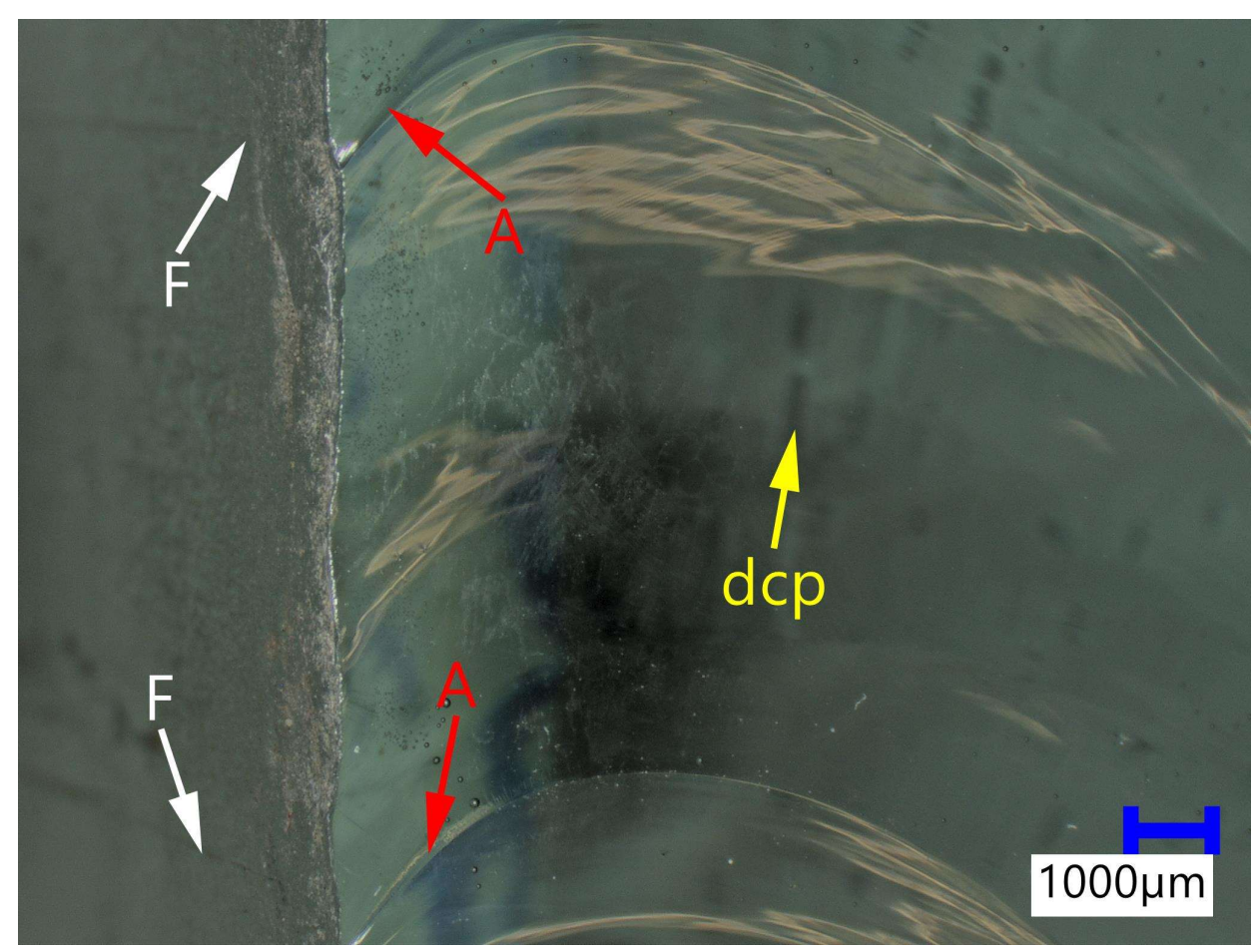

Fig. 17: Crack front surface and side view of a "Float $10 \mathrm{~mm} * 5,1120^{\circ} \mathrm{C},-50^{\circ} \mathrm{C} / \mathrm{hr}$ " specimen. The insufficient homogenization between the float plies due to a short dwell time at top temperature $(2 \mathrm{~h})$ results in subtle bubble veils at the fusion zones and linear marks at the side surface ("F"). The crack will show a momentary arrest ("A") at these lines

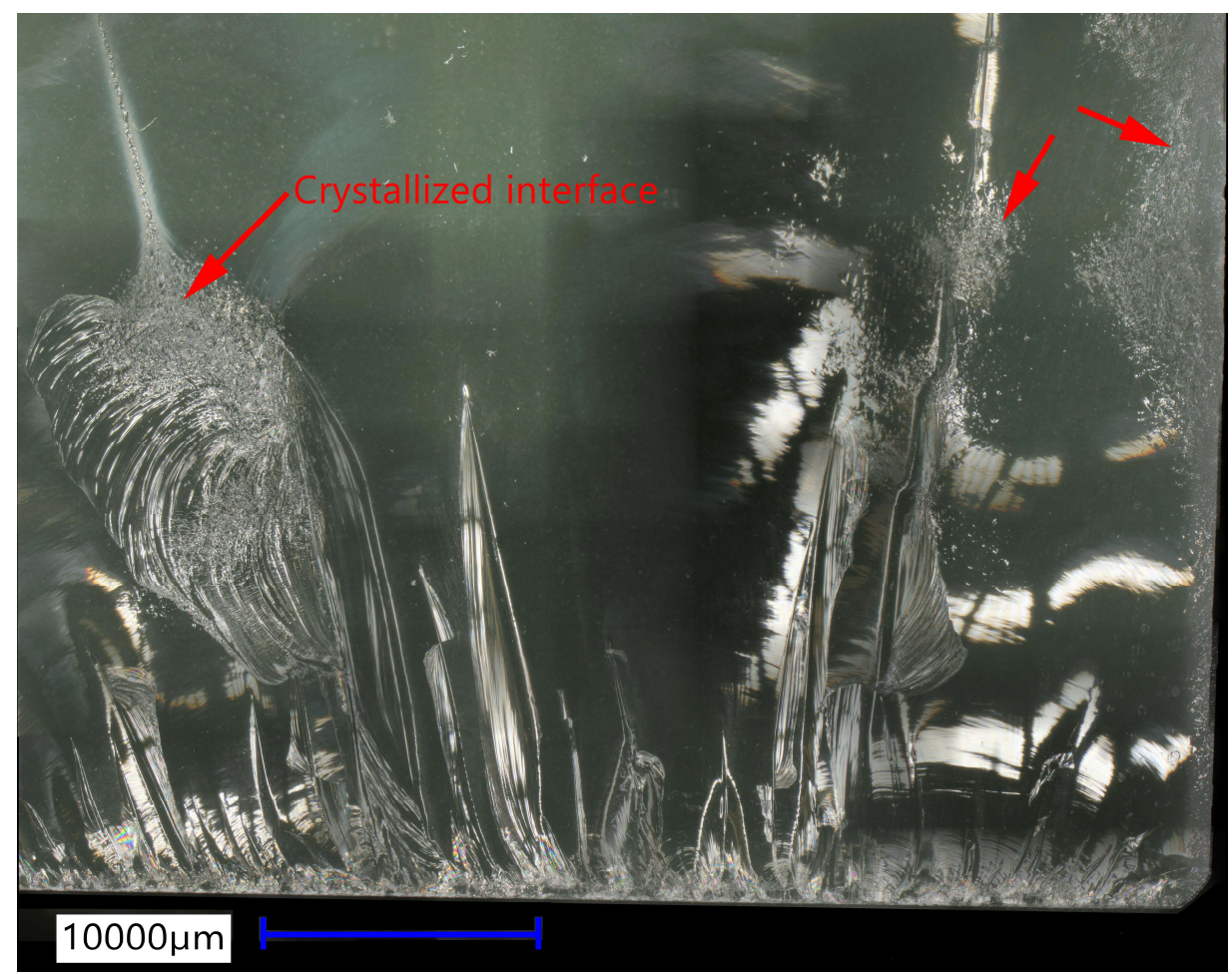

Fig. 18: Crack front of a fused "Float $10 \mathrm{~mm} * 5,970^{\circ} \mathrm{C}$ " specimen, with the crystalline interfaces oriented in parallel to the force direction during testing. The crack front will interact with the crystalline interface if encountered during its propagation, but will not change its direction of growth 

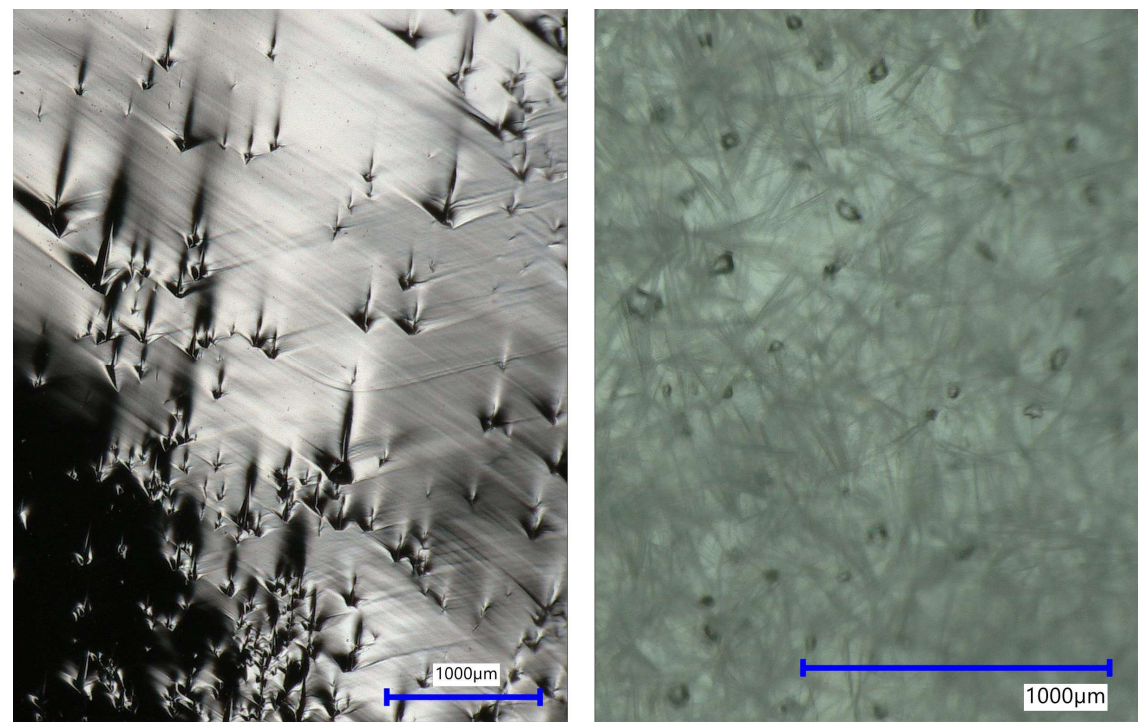

Fig. 19: Detail from specimen in Fig. 18 (right red arrows) showing the formation of wing gulls when the crack front encounters the crystalline interface (left). On the right, an image of the crystalline interface, showing the existence of acicular crystals

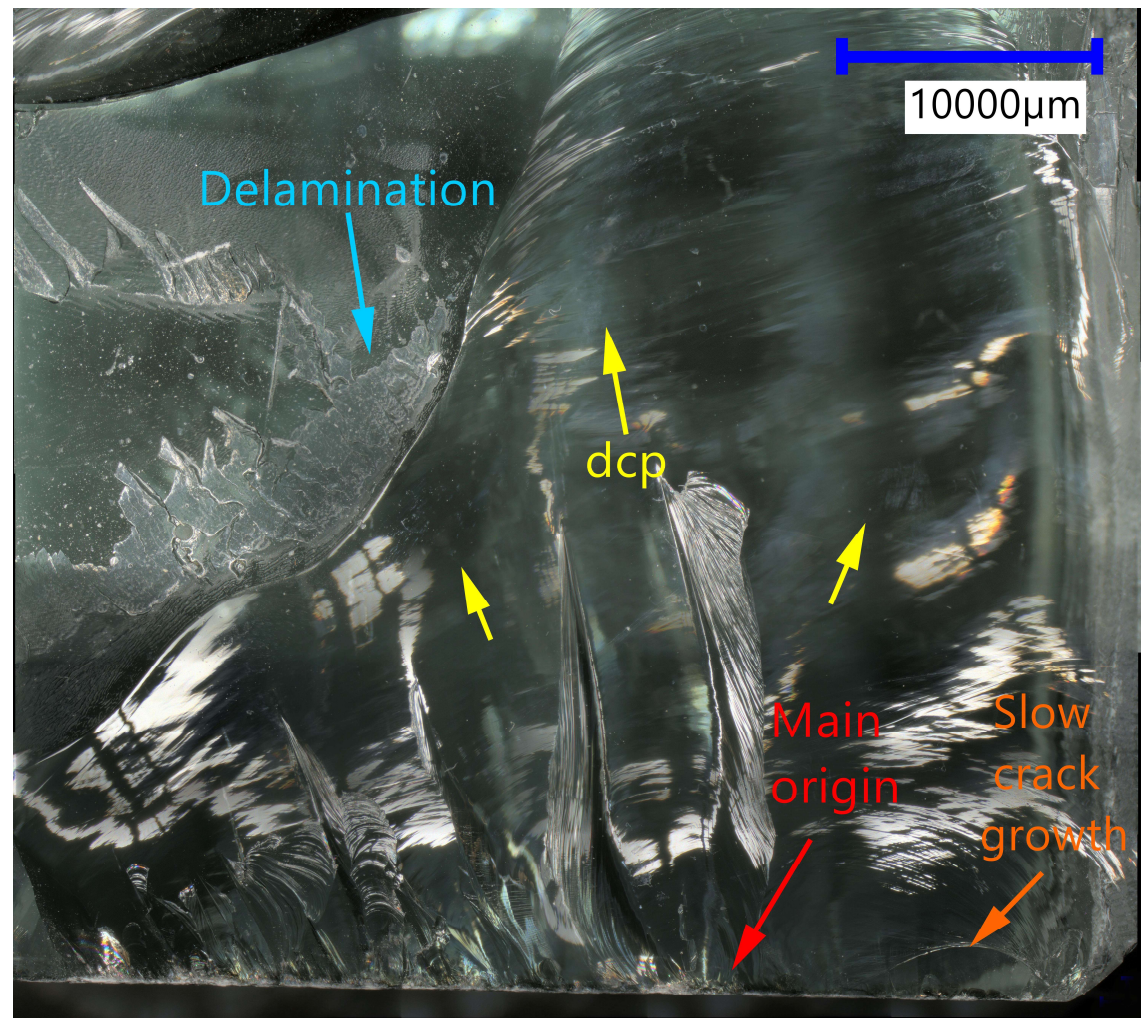

Fig. 20: Crack front surface of a glued "Float $10 \mathrm{~mm} * 5$ Delo" specimen, with its adhesively bonded interfaces being in parallel to the force direction during testing. Once the adhesive interface is encountered, delamination will occur and the crack will move along the glued surface of lower stiffness

Such zones, although in theory weaker, are not considered disruptive enough to the glass network (as long as they are not stress inducing), so that a fast propagating crack will alter its path. Such path alteration is only observed in the (parallel to the force) glued specimens, where partial delamination will occur (Fig. 20).

A higher degree of interaction is observed when crystalline zones are incorporated in the glass (Fig. 21). 
Most characteristic is the example of the fused Borosilicate $\left(970^{\circ} \mathrm{C}\right)$, which contains two crossed $50 * 50$ $\mathrm{mm}$ crystalline interfaces, one perpendicular to the toolbit and the second one in parallel to the bottom surface (Fig. 21 right). The perpendicular to the toolbit crystalline interface -due to its expected higher hardness than the surrounding glass- seems to divide the glass sample in two distinct parts. This can be observed at the bottom surface, where around the interface, only minimum lateral damage occurs, in contrast to the middle zone of the two glass parts (Fig. 23). At the crack front surface, two distinct fracture origins and intense shear hackle lines are observed at the middle of each glass part.

The crack eventually propagates across the crystalline borders, yet intense median-cracking and shear lines are observed along the interface. The crystalline interface, at least in this thickness $(\approx 70-85 \mu \mathrm{m})$ and for this specimen size $(50 \mathrm{~mm})$, is not sufficient to completely arrest the crack propagation, as in the example of the (perpendicular to the force) glued specimens (Fig. 22).
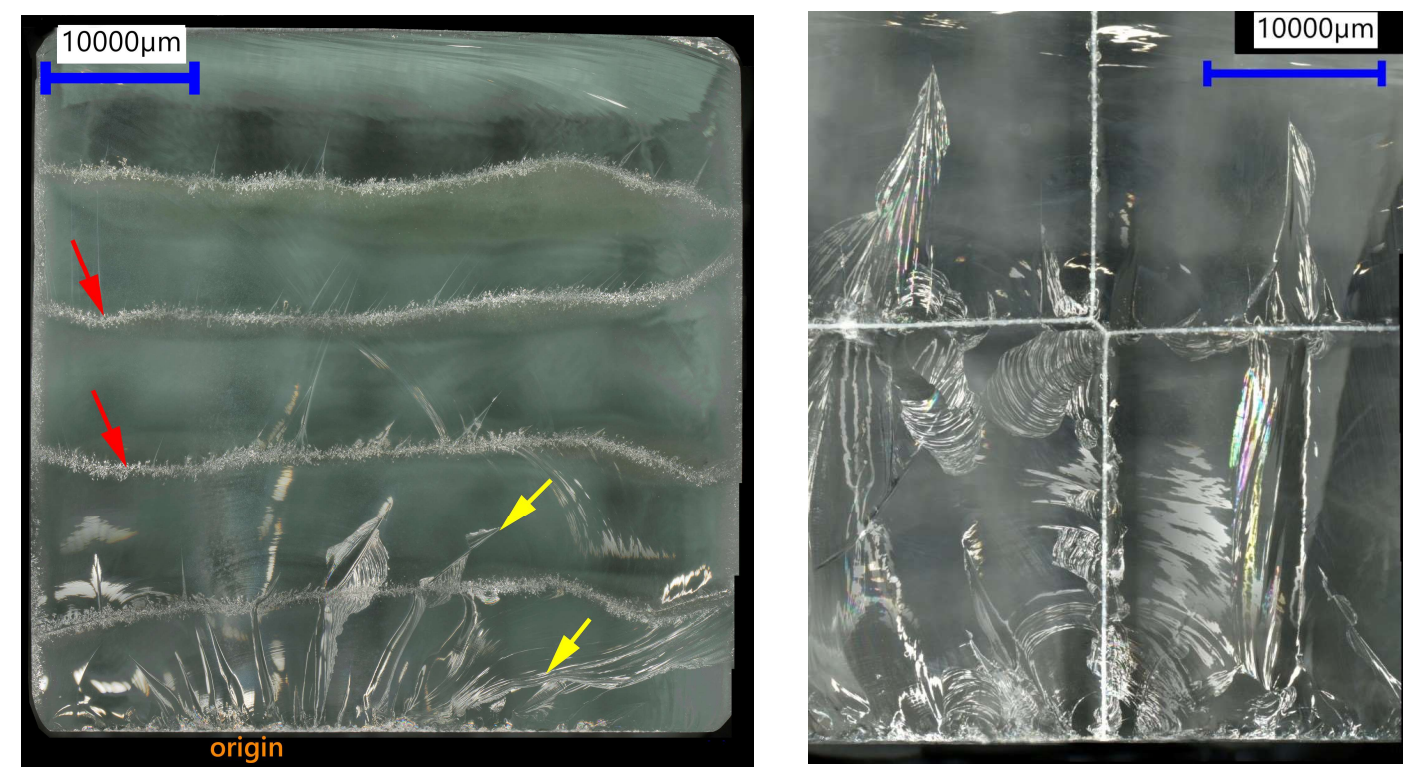

Fig. 21:Crack propagation in a fused "Float $970^{\circ} \mathrm{C}$ " specimen with crystalline interlayers (red arrows) oriented perpendicularly to the force direction (left) and in a fused "Borosilicate $970^{\circ} \mathrm{C}$ " specimen (right). The crack may momentarily slow down or arrest when encountering a crystalline interface, but it will not stop from propagating. Hackle lines (for indication see yellow arrows, left figure) may turn into twist hackle upon encountering a crystalline interface
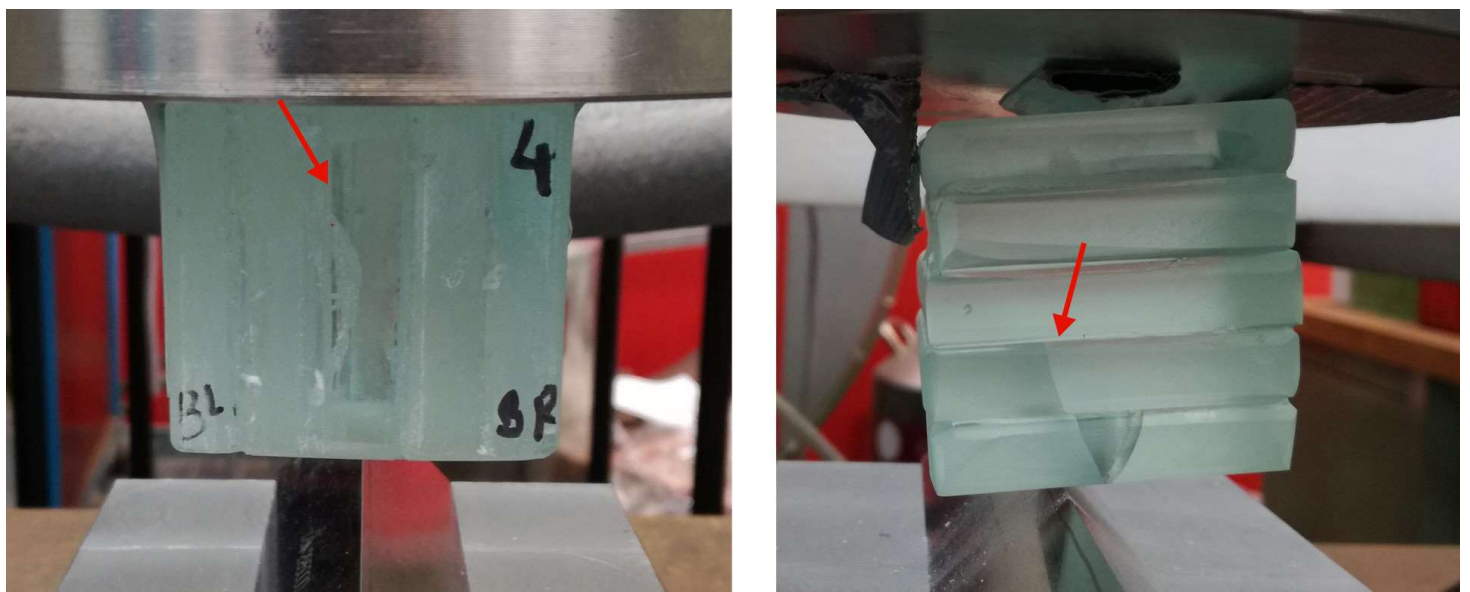

Fig. 22:Float specimens glued with DELO and tested in parallel (left) or perpendicular (right) orientation. In the left case, the crack will propagate throughout the specimen and move along the adhesive layer once it reaches it, while in the right case, the propagation will be completely arrested by the adhesive interface 

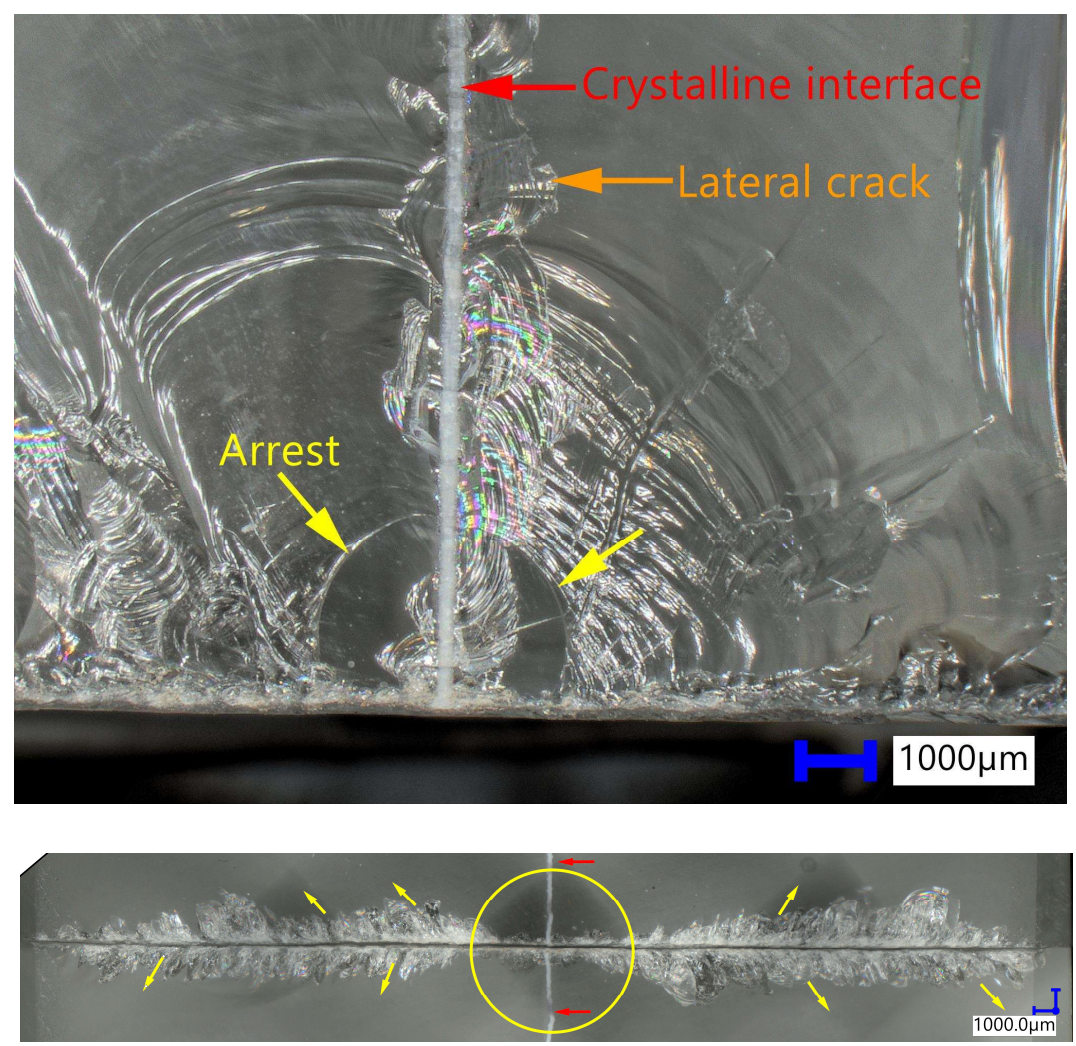

Fig. 23: Crack front (top) and bottom surface (bottom) of a fused "Borosilicate $970^{\circ} \mathrm{C}$ " specimen. The perpendicular to the toolbit crystalline interface is separating the component in two parts

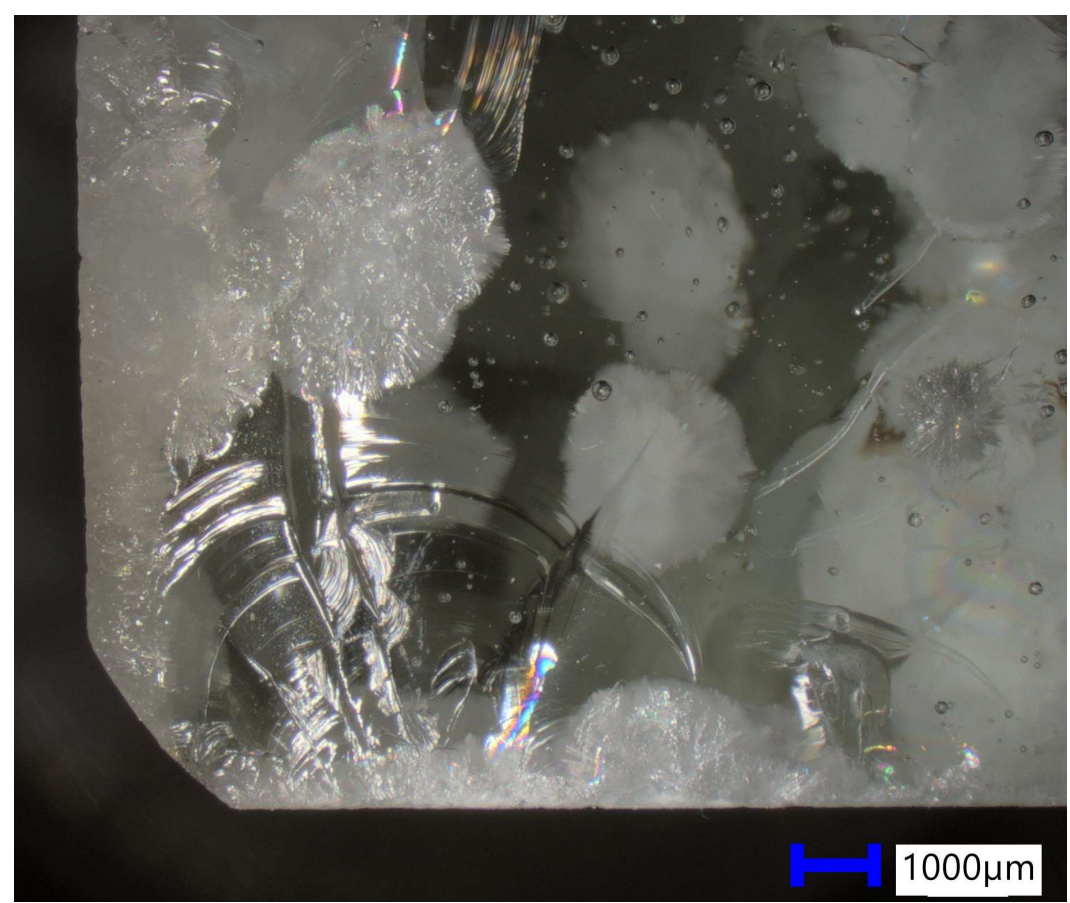

Fig. 24: Fracture origin of a heat-treated "Clear bottle cullet" specimen, showing the interchange between glassy and crystalline material at the process zone of the crack 


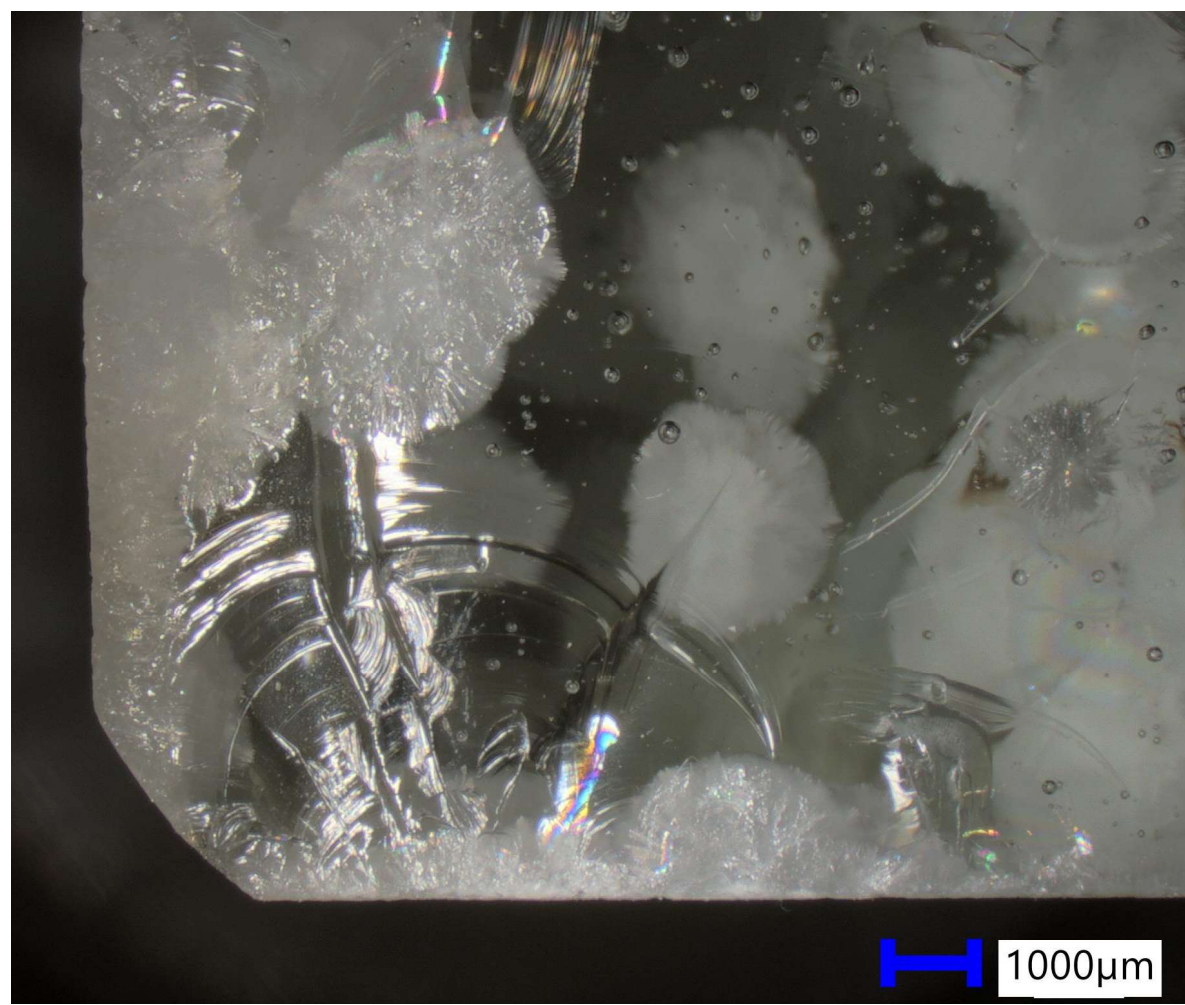

Fig. 25: Crack front of a fused "Low-iron float powder $970^{\circ} \mathrm{C}$ specimen. The intense porosity at the process zone of the crack is weakening the specimen

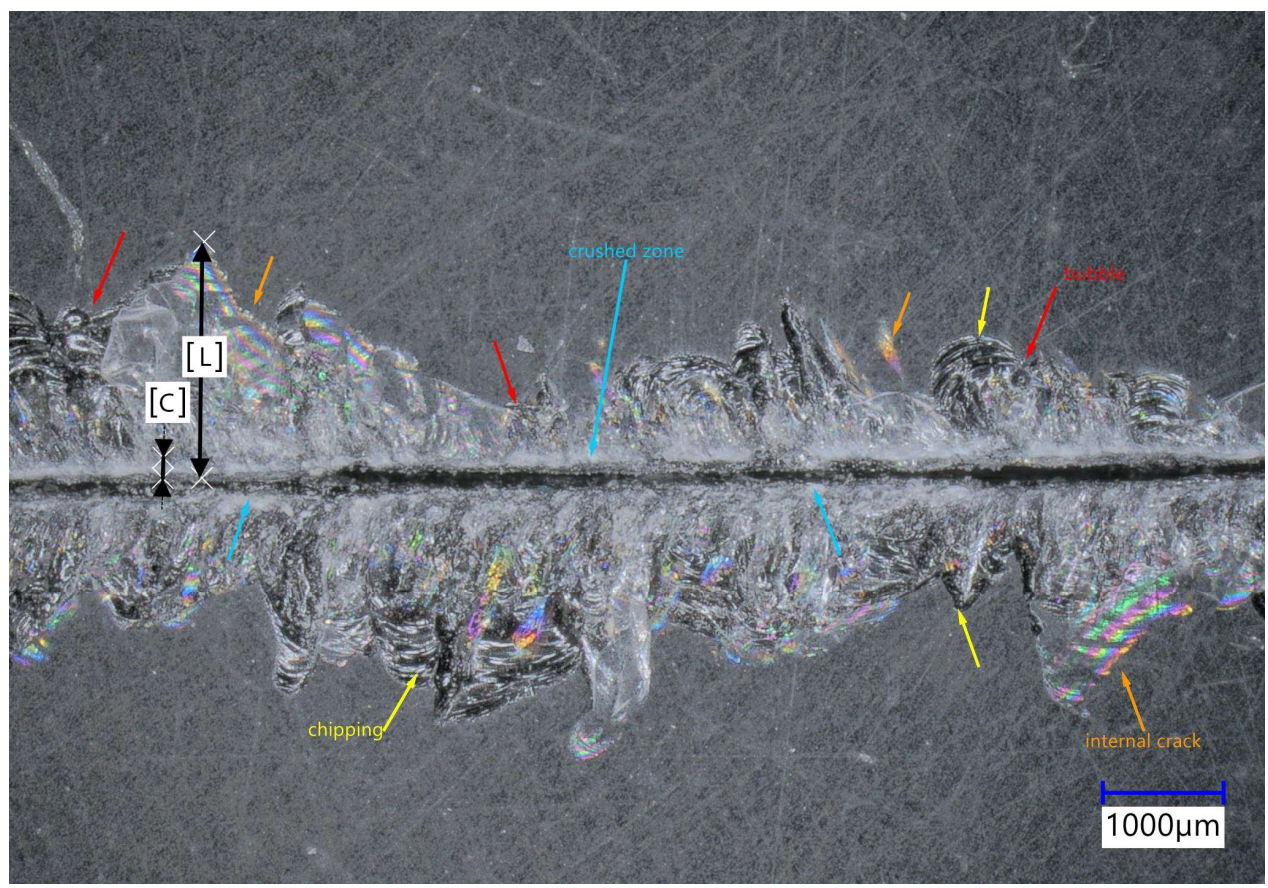

Fig. 26: Bottom surface of a "Sibelco Clear bottle" specimen, showing the zone in contact with the toolbit and subsequently the zone of crushed glass and the lateral damage caused by the increasing pressure. The extent of Crushing (C) and Lateral damage (L) are measured in each sample as indicated in the image above 

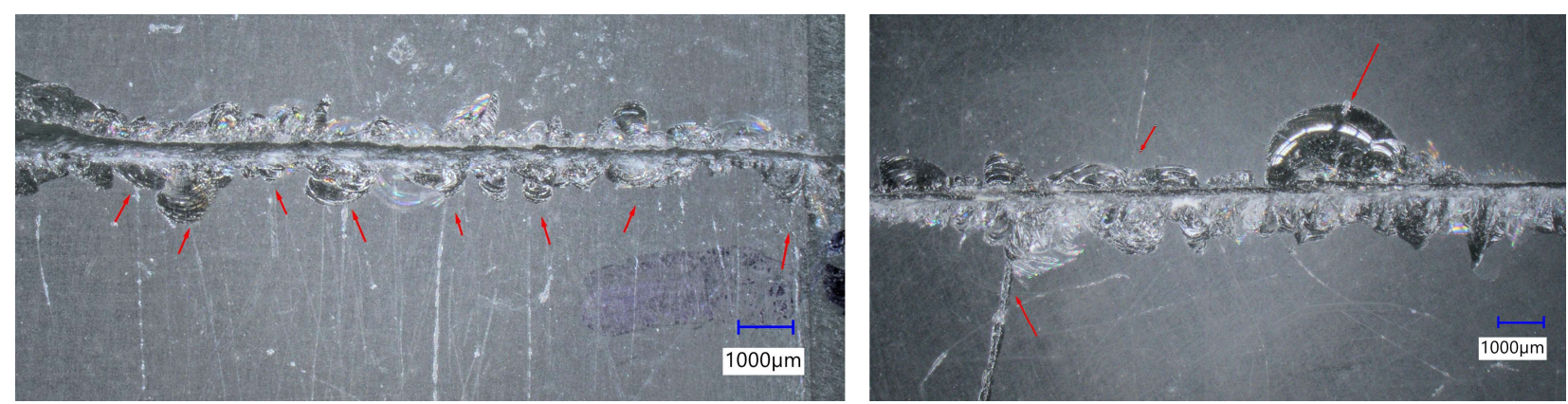

Fig. 27: Bottom surface of "Sibelco Clear bottle" specimen showing the link of lateral damage to surface defects such as scratches or bubbles
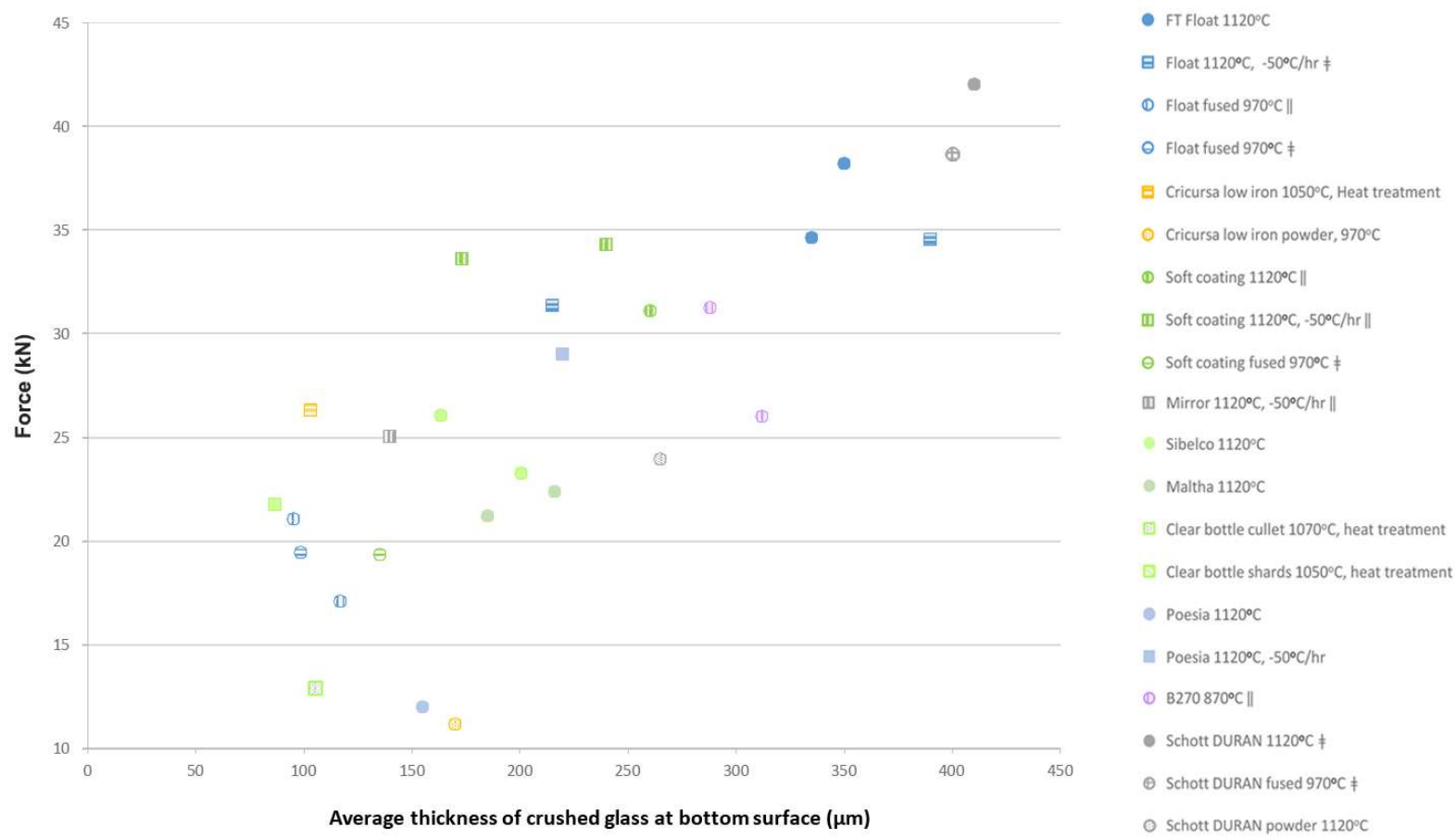

Fig. 28: Extent of crushing in relation to the splitting force at failure. Only fully supported specimens are included in the graph

Examples of specimens having an alternating structure of glassy and crystalline material exposed to the toolbit line (e.g., Clear bottle cullet/shards, heat-treated, Fig. 26) or a high porosity (Fig. 27) show a fluctuating response (e.g., densification, stable cracking) during loading. The uneven processing of the load due to material property differences of the two structures is stress-inducing and accelerates failure.

Regarding the bottom surface and likewise to the crack front surface, a crushed zone of maximum 500 $\mu \mathrm{m}$ thickness is observed followed by an array of median-radial cracks of maximum $5 \mathrm{~mm}$ (either at the surface in the form of chips, or in the sub-surface, Fig. 26). The extent of the lateral damage (both crushing and chipping) is directly related to the force
(Fig. 28 and 30). However, specimens that have been heat-treated or slowly cooled, show relatively less damage. On the other hand, the heat-treated "Clear bottle cullet" specimen, due to the inherent intermix between crystalline and glassy structure, is more prone to lateral damage. The presence of scratches (due to post-processing damage) or pores (e.g., crystalline material from mould contamination, cut bubbles) at the bottom surface often seems to intensify the occurrence of chipping (Fig. 29). Significant unevenness in the thickness of the crushed layer along the contact line, is a telltale sign of specimen tilting during testing. These specimens are discarded from the surface damage analysis, since they are not comparable to the fully supported specimens. 

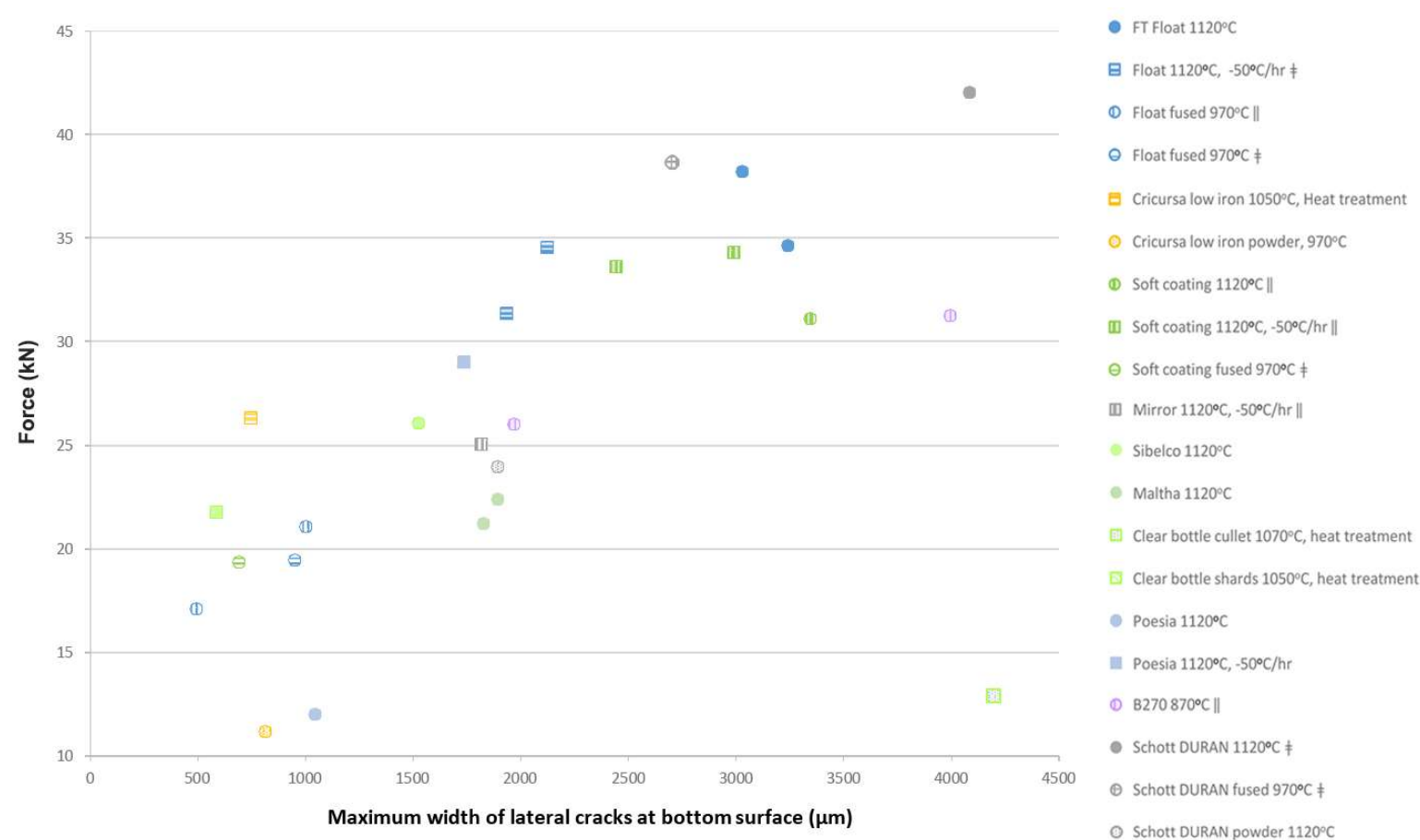

Fig. 29: Maximum width of lateral damage in relation to the splitting force at failure. Only fully supported specimens are included in the graph

\section{Discussion}

\section{Comparison between Splitting and Four-Point Bending Experiments}

A comparison between the resistance of cast glass to catastrophic fracture due to a pressing sharp indenter, to its strength in flexure due to bending is made. For this comparison, current data from the splitting experiment and previously obtained data from four-point bending experiments (Bristogianni et al., 2020; 2021), are used.

Reversed results can be seen, by comparing the obtained data of homogeneous Borosilicate, FT Float and Poesia glass. More specifically, the flexural strength increases in the order of Borosilicate $1120^{\circ} \mathrm{C}(44 \mathrm{MPa})$ $<$ FT Float $1120^{\circ} \mathrm{C}(45 \mathrm{MPa})<$ Poesia $1070^{\circ} \mathrm{C}(58 \mathrm{MPa})$, while the fracture resistance decreases respectively to 42 $\mathrm{kN}>36.4 \mathrm{kN}>28.3 \mathrm{kN}$. Similarly for the fused specimens, the Borosilicate $970^{\circ} \mathrm{C}$ showed an average flexural strength of $13.9 \mathrm{MPa}$, which was the lowest value from all tested glass types and the $2^{\text {nd }}$ highest fracture resistance force, $38.7 \mathrm{kN}$. On the contrary, although the Fused Float $970^{\circ} \mathrm{C}$ had a higher flexural strength $(33.3 \mathrm{MPa})$, its fracture resistance in the cube splitting test was reduced to $16.6 \mathrm{kN}$. The above reverse results do not imply a

\footnotetext{
${ }^{4}$ The Young's modulus, according to Makishima and Mackenzie (1973) is related to the Atomic Packing Density (APF) and the total dissociation energy $\left(G_{t}\right)$ that reflects the bond strength:
}

straightforward relationship however; the fused float versus the homogeneous float specimen remains weaker in both tests and so does the industrially cast Poesia glass versus the kiln-cast version.

The distinct differences between the two tests in the performance of the different glass types highlight the different mechanisms involved in the failure of the specimens. In the four-point bending experiment, a farfield tensile stress is developed at the bottom zone of the beam, reaching a maximum level at the bottom surface area between the loading rollers. Any flaws located in this zone, either inherent (e.g., stones, cord, bubbles) or external (e.g., post-processing damage, impact, scratches), will be activated inducing stress concentration to the surrounding glass and with the most critical flaw leading to catastrophic failure. The strength of glass in this case is highly dependent on the set of flaws that each glass type is prone to have, in combination to its material properties resulting from the chemical composition and thermal history. The stiffness $^{4}$ of glass plays a prominent role in this process. However, although a high bond strength is desired to resist fracture, a slightly more open structure is beneficial as it allows for minor deformations around the flaws and thus stress relief during loading. In that

$$
E=2 \cdot A P E \cdot G_{t}
$$


sense, the borosilicate glass that has a much lower stiffness $(\mathrm{E}=62 \mathrm{GPa})$ than FT Float $(\mathrm{E}=75 \mathrm{GPa})$ will have as well lower flexural strength, yet the Poesia glass with $\mathrm{E}=70-72 \mathrm{GPa}$ but also a higher molar volume than FT Float due to the increased $\mathrm{Na}_{2} \mathrm{O} / \mathrm{CaO}$ ratio, will be stronger (Bristogianni et al., 2021). Nonetheless, given that each glass is characterized by a unique set of flaws- whose distribution, shape and quantity are to a great extent random- the exact interaction between chemical composition and glass structure cannot be elucidated at this stage ${ }^{5}$.

In the case of the splitting test, given the prominent role of the indenter as the cause of failure, the uncertainty created by the incidental population and type of flaws is to some extent reduced. As the sharp toolbit gradually gets inserted deeper in the material and lateral tension builds up, the glass will initially respond by permanently deforming. According to Rouxel (2008), this deformation is mainly in the form of densification rather than shear flow for silicate-based glasses, due to low Poisson's ratio (v). More specifically, the lower the $v$ in silicate glasses, the higher the displacement of matter and thus the relaxation of stress, leading to a higher Crack Resistance (CR, resistance to crack initiation). A higher crack resistance delays the formation of median-radial cracks that will gradually weaken the glass cubes to a more decisive extent than the inherent flaws they may have. Once such cracks are formed and the pressure from the toolbit continues to increase, then the fracture surface energy $^{6}(\gamma)$ and consequently the fracture toughness $\left(K_{I c}\right.$, resistance to crack growth) of glass become dominant in resisting the unstable propagation of the growing crack. Yet, although singular defects in the glass structure will have a much less prominent role in the splitting test, once the defects start to significantly degrade the glass zone in contact with the toolbit (e.g., in the case of the porous and crystallized glass specimens, or the heavily crystallized "Clear bottle cullet, heat-treated" specimen), then a significant reduction in the fracture resistance will be observed.

${ }^{5}$ Distinguishing these roles may not be appear directly relevant in the engineering practice for calculating a cast glass structure. However, this deeper understanding is important for engineering stronger cast glass components, improving the casting production process and conducting responsible quality control.

${ }^{6}$ Fracture surface energy is the energy linked to the formation of new surfaces during fracture. When the introduced mechanical energy cannot be further accommodated by stress relaxation, it is energetically preferable for a brittle material to fracture, converting this energy into surface energy. According to Griffith (1921), crack propagation will occur when:

$S=\sqrt{\frac{2 \cdot E \cdot \gamma}{\pi \cdot c}}$

With $S$ being the applied stress and c the half-length of an elliptical flaw. The formula shows that a higher fracture surface energy leads to a higher amount of stress that can be accommodated prior to fracture.
The splitting test therefore measures the complete process from crack initiation due to sharp contact loading, to fracture propagation and catastrophic failure:

\section{Fracture resistance $=$ \\ Crack initiation resistance $\cdot$ Crack propagation resistance}

To better comprehend the splitting test results, a deeper look at the relationship of the glass composition and structure to the crack resistance and fracture surface energy is required.

\section{The Effect of Chemical Composition, Thermal History and Mesostructure to the Fracture Resistance of Cast Glass}

There is no systematic correlation between crack resistance and fracture toughness, according to research conducted by To et al. (2020), yet both parameters depend on the glass composition and thermal history (e.g., cooling rate). Glasses with simultaneously high $\mathrm{CR}^{7}$ and $K_{I c}$ values, would then exhibit low-brittleness behaviour.

More specifically, the crack initiation resistance is controlled by the extent to which the glass can densify or shear in the process zone under the indenter, with densification being favoured in glasses with small Poisson's ratio (Sellappan et al., 2013). A more open glass structure, reflected by a lower Atomic Packing Fracture (APF) and higher molar volume $\left(V_{m}\right)$, will allow for more deformation, leading to a higher crack initiation load and less brittleness (Sehgal and Ito, 1999; Hasdemir et al., 2015). Table 3 shows the calculated APF and $V_{m}$ of the tested glasses based on the chemical composition. As it can be seen, the Schott DURAN borosilicate presents the lowest APF and highest $V_{m}$ that suggests a more open structure $^{8}$. The SLS glasses show on the other hand the lowest $V_{m}$ from the tested glasses. The B270 and the Poesia glass have a higher molar volume than the SLS glasses, due to their $\mathrm{K}_{2} \mathrm{O}$ content and the higher alkali to calcia ratio (Sehgal and Ito, 1999).

${ }^{7}$ Crack Resistance CR is often measured using the method suggested by Wada et al. (1974): A Vicker's indenter creates imprints at various loads and the number of corners presenting radial cracks is evaluated. Januchta and Smedskjaer (2019) stress however that CR refers to the critical load for radial crack initiation and not for all types of cracks under a sharp indenter (e.g., lateral cracks). The value is also influenced by the testing and atmospheric conditions. In this study, CR is used to compare different silicate-based glass compositions in a quantitative manner and less attention is given to the actual value.

${ }^{8}$ The less rigid glass structure is attributed to the higher content of silica and the portion of threefold-coordinated boron in the network (66\% as calculated using the formulas by Yun and Bray (1978)). Kato et al. (2010a; 2010b) showed that, as the tetrahedral boron is responsible for a rigid $3 \mathrm{D}$ glass structure that prohibits densification and therefore increases the residual stress, a reduction in its percentage will increase the CR. 
Telesilla Bristogianni et al. / International Journal of Structural Glass and Advanced Materials Research 2021, Volume 5: 195.225 DOI: $10.3844 /$ sgamrsp.2021.195.225

Table 3: (part 1). Chemical composition and mechanical properties of the studied and relevant reference glasses

\begin{tabular}{|c|c|c|c|c|c|c|c|c|c|c|c|c|c|c|}
\hline \multirow[b]{2}{*}{ Glass type } & \multirow[b]{2}{*}{ Name* } & \multicolumn{12}{|c|}{ Composition (wt\%) } & \multirow[b]{2}{*}{ Source } \\
\hline & & $\mathrm{SiO}_{2}$ & $\mathrm{~B}_{2} \mathrm{O}_{3}$ & $\mathrm{Na}_{2} \mathrm{O}$ & $\mathrm{K}_{2} \mathrm{O}$ & $\mathrm{CaO}$ & $\mathrm{MgO}$ & $\mathrm{Al}_{2} \mathrm{O}_{3}$ & $\mathrm{TiO}_{2}$ & $\mathrm{Fe}_{2} \mathrm{O}_{3}$ & $\mathrm{Sb}_{2} \mathrm{O}_{3}$ & $\mathrm{ZnO}$ & $\mathrm{BaO}$ & \\
\hline \multirow[t]{6}{*}{ Soda Lime Silica } & FT float & 75.4 & & 12.4 & & 7.6 & 4 & 0.4 & 0.02 & 0.09 & & & & {$[1]$} \\
\hline & Float IFS-SGT & 72.4 & & 12.3 & 0.1 & 9.9 & 4.1 & 0.6 & 0.06 & 0.07 & & & & [1] \\
\hline & Cricursa low iron & 74.0 & & 12.7 & & 8.4 & 4.2 & 0.55 & & 0.02 & & & & {$[1]$} \\
\hline & Starphire PPG & 74.6 & & 13.3 & & 8.9 & 3 & 0.04 & & & & & & [1] \\
\hline & Pilkington soft coating & 74.4 & & 12.5 & 0.15 & 8.2 & 3.9 & 0.55 & 0.03 & 0.06 & & & & [1] \\
\hline & Clear bottle & 72.7 & & 12.0 & 0.5 & 10.0 & 3 & 1.3 & 0.045 & 0.17 & & & & [1] \\
\hline \multirow[t]{2}{*}{ Modified Soda Lime } & Poesia & 72.1 & 2.5 & 15.9 & 1.9 & 6.1 & 0.06 & 0.3 & & & 0.9 & & & {$[1,9]$} \\
\hline & $\mathrm{B} 270$ & 71.8 & & 10.1 & 6.3 & 5.2 & & 2 & 1.8 & & 0.4 & 2.2 & 0.03 & {$[1]$} \\
\hline Borosilicate & Schott DURAN & 80.0 & 13.0 & 3.5 & 0.5 & & & 2.7 & & & & & & {$[1,11]$} \\
\hline Amorphous silica & $\mathrm{a}-\mathrm{SiO}_{2}$ & 100.0 & & & & & & & & & & & & [14] \\
\hline
\end{tabular}

* Only the glasses in bold characters are experimentally tested in this study. The Starphire and Amorphous silica glasses are included in this table as a reference

[1] XRF measurements conducted by Ruud Hendrikx; [2] Calculated using viscosity model by Fluegel (2007a); [3] Calculated using density model by Fluegel (2007b); [4] Yet unpublished prior work by the authors; [5] Vitro Architectural Glass (2020); [6] Quinn and Swab (2017); [7] Calculated as G = E/[2(1+v)]; [8] Calculated as K= E/[3(1-2v)]; [9] Personal correspondence with Poesia; [10] Schott (2013); [11] Schott (2015); [12] Schott (2017); [13] Abrisa Technologies (2014); [14] Heraeus Holding (2013); [15] Rouxel (2017); [16] Sellappan et al. (2013)

Table 3: (part 2). Chemical composition and mechanical properties of the studied and relevant reference glasses

\begin{tabular}{|c|c|c|c|c|c|c|c|c|c|c|c|c|}
\hline Name* & $\begin{array}{l}\text { Annealing } \\
\text { Point } 10^{13} \\
\mathrm{dPa} \cdot \mathrm{s} \\
\left({ }^{\circ} \mathrm{C}\right)\end{array}$ & $\begin{array}{l}\text { Density } \\
\left(\mathrm{g} / \mathrm{cm}^{3}\right)\end{array}$ & $\begin{array}{l}\text { Knoop } \\
\text { micro } \\
\text { hardness } \\
\left(\mathrm{kgf} / \mathrm{mm}^{2}\right)\end{array}$ & $\begin{array}{l}\text { Molar } \\
\text { volume } \\
\mathrm{V}_{\mathrm{m}} \\
\left(\mathrm{cm}^{3} / \mathrm{mol}\right), \\
\text { calculated }\end{array}$ & $\begin{array}{l}\text { APF } \\
\text { Calculated } \\
\text { based on } \\
\text { Shannon's } \\
\text { ionic radii }\end{array}$ & $\begin{array}{l}\mathrm{G}_{\mathrm{t}} \quad \text { Total } \\
\text { Dissociation } \\
\text { energy } \\
\left(\mathrm{kJ} / \mathrm{cm}^{3}\right) \text {, } \\
\text { calculated } \\
\text { using Inaba } \\
\text { et al. }\end{array}$ & $\begin{array}{l}\mathrm{E}(\mathrm{GPa}) \\
\text { from } \\
\text { literature }\end{array}$ & $\begin{array}{l}\text { Shear } \\
\text { modulus } \\
\mathrm{G}(\mathrm{GPa}) \\
\text { literature }\end{array}$ & $\begin{array}{l}\text { Bulk } \\
\text { modulus } \\
\mathrm{K}(\mathrm{GPa}), \\
\text { literature }\end{array}$ & $\begin{array}{l}\text { Poisson's } \\
\text { ratio } v \\
\text { calculated } \\
\text { using } \\
\text { Makishima } \\
\text { and } \\
\text { Mackenzie } \\
\text { formula } \\
\text { and } \\
\text { Shannon's } \\
\text { APF }\end{array}$ & $\begin{array}{l}\text { Poisson's } \\
\text { ratio } v \\
\text { (literature) }\end{array}$ & $\begin{array}{l}\text { Vicker's } \\
\text { hardness } \\
\text { calculated } \\
\text { using } \\
\text { Yamane } \\
\text { and } \\
\text { Mackenzie } \\
\text { formula }\end{array}$ \\
\hline FT float & 553 [2] & $2.47[3]$ & & 23.92 & 0.4920 & 64.83 & & & & 0.218 & & \\
\hline Float IFS-SGT & $562[2]$ & $2.5[4]$ & & 23.8 & 0.4907 & 64.87 & $71[4]$ & & & 0.217 & & 6.9 \\
\hline $\begin{array}{l}\text { Cricursa low } \\
\text { iron }\end{array}$ & 554 [2] & $2.48[3]$ & & 23.73 & 0.4937 & 64.85 & & & & 0.219 & & \\
\hline Starphire PPG & $545[5]$ & $\begin{array}{l}2.48[3] \\
2.51[5]\end{array}$ & $\begin{array}{l}470 \\
\text { (Force: } \\
500 \mathrm{gf} \text { ) [5] }\end{array}$ & 23.55 & 0.4997 & 64.03 & $73.1[5]$ & $\begin{array}{ll}30.4 \pm 0.3 \\
{[6]} & 29.9 \\
{[7]} & \end{array}$ & $\begin{array}{l}42.2 \pm 0.9 \\
{[6]} \\
{[8]}\end{array}$ & 0.222 & $0.22[5]$ & 7.1 \\
\hline $\begin{array}{l}\text { Pilkington soft } \\
\text { coating }\end{array}$ & 554 [2] & $2.48[3]$ & & 23.85 & 0.4930 & 64.76 & & & & 0.218 & & \\
\hline Clear bottle & $564[2]$ & $2.49[3]$ & & 23.88 & 0.4943 & 64.72 & & & & 0.219 & & \\
\hline Poesia & $\approx 520[2]$ & 2.49 [3] & 500 & 24.65 & 0.4997 & 61.83 & $69[4]$ & & & 0.222 & & 6.6 \\
\hline B270 & $535[10]$ & 2.49 [3] & $\begin{array}{l}\text { (Force: } \\
\text { 100gf) } \\
{[10]}\end{array}$ & 25.26 & 0.4939 & 62.91 & $71.1[10]$ & $29[10]$ & $42.4[8]$ & 0.219 & $0.22[10]$ & 6.8 \\
\hline $\begin{array}{l}\text { Schott } \\
\text { DURAN }\end{array}$ & $560[12]$ & $\begin{array}{l}2.23 \\
{[11]}\end{array}$ & $\begin{array}{l}480 \\
\text { (Force } \\
100 \mathrm{gf}) \\
{[13]} \\
\end{array}$ & 27.54 & 0.4767 & 64.1 & $63[11]$ & 26.3 [7] & $35[8]$ & 0.209 & $0.20[11]$ & 5.9 \\
\hline $\mathrm{a}-\mathrm{SiO}_{2}$ & 1100 [14] & 2.2 & $\begin{array}{l}591-632 \\
{[14]}\end{array}$ & 27.31 & 0.4561 & 68 & $70[15]$ & $30.4[16]$ & $33.3[16]$ & 0.195 & 0.15 [15] & 6.6 \\
\hline
\end{tabular}

The ability of the borosilicate glass to densify more under a sharp load, is also seen by the lower Poisson's ratio ( 0.2 versus 0.22 of SLS glass, Table 3$)$, which according to Makishima and Mackenzie (1975) is directly related to the APF through the formula:

$$
v=0.5-\frac{1}{7.2 \cdot A P F}
$$

Crack resistance is also depended on the bond strength (To et al., 2020), as the stronger the bonds in the network, the more difficult to break. Januchta et al. (2020) also correlate CR to the Bulk modulus ${ }^{9}$ stating that flexible glasses can distribute the residual stress in a larger field. At this point, it should be elaborated that Hardness, which quantifies the resistance of a ceramic material to deformation and densification, is not inversely related to CR (Table 4). In other words, the resistance of a glass to crack initiation cannot be predicted by solely reviewing its hardness (a property often and easily tested in glass and ceramics, Table 5), as it is the optimum combination of bond strength and

${ }^{9}$ For isotropic materials, the Bulk modulus $\mathrm{K}$ is related to the Young's modulus and Poisson's ratio as:

$K=\frac{E}{3(1-2 v)}$ 
atomic packing density that contributes to a high cracking resistance ${ }^{10}$.

Proceeding now to the next phase, resisting the propagation of an already created crack, the surface energy $(\gamma)$ of the material becomes of crucial importance. The fracture surface energy is linked to the surface density of representative structural units and the bond strength (Rouxel, 2017) ${ }^{11}$. Experimentally identified (by Wiederhorn 1969; Nakayama, 1965) or theoretically calculated (by Rouxel, 2017) $\gamma$ values for glass (Table 6) show that borosilicate glass- of a composition similar to DURAN Schott- has a higher $\gamma$ than SLS glass. This difference is not directly evident if only the $K_{I c}{ }^{12}$ value of these two glass types is considered and which according to the testing set-up and environmental conditions can be identical (Table 6).

Therefore, it is concluded that for a high resistance to fracture, a balanced combination of flexibility (empty space) in the network and strong bonds are required. By evaluating the glasses included in this study according to their molar volume $V_{m}$ and dissociation energy $G_{t}$ (calculated based on Inaba et al., 1999) in Fig. 30, it can be predicted which glass types will show higher resistance to crack initiation due to low $V_{m}$ (Poesia, B270), which will show higher resistance to crack propagation due to high $G_{t}(\mathrm{SLS})$ and which will perform well in both cases (Borosilicate).

Nonetheless, the above argumentation only takes into account the chemical composition of the glass and neglects its thermal history and flaw population. A faster cooling and annealing scheme can reduce the polymerization of the SLS glass network leading to lower hardness (Gross and Tomozawa, 2008), E modulus and brittleness (Ito and Taniguchi, 2004). Moreover, surface flaws and residual stress weaken the glass and decrease the crack initiation load.

The fused specimens included in this study, due to their prolonged dwell time at the crystallization-risk temperature range, develop crystalline zones at the surface (and bulk) of the cast components that change the way the glass interacts with the toolbit. The harder structure or gradient between glassy and crystalline material (e.g., "Clear bottle cullet $1070^{\circ} \mathrm{C}$, heat-treated") decreases the crack initiation load, leading to a lower fracture resistance load. To an even greater extent, the porous crystalline SLS glass specimen, due to its extensively open/broken network, has a lower

\footnotetext{
${ }^{10} \mathrm{As}$ an indication of the parameters influencing the hardness of a glass, the following formula is insightful, developed by Yamane and Mackenzie (1974) for calculating the Vicker's hardness number of glasses from their chemical composition:

$H_{V}=0.051 \cdot E\left(\frac{a}{0.462+0.09 A P F-A P F^{2}}\right)^{1 / 2}$

where, $a$ is a factor relating the average single bond strength to $\mathrm{Si}-\mathrm{O}$ bond strength.

${ }^{11}$ According to Rouxel (2017), the intrinsic $\gamma$ of a glass can be calculated based on the number and type of bonds involved in the fracture, in the following manner:
}

resistance to fracture. Glasses with a slower cooling scheme $\left(-50^{\circ} \mathrm{C} / \mathrm{hr}\right)$ showed more resistance to fracture (e.g., Poesia cast variants), while the "Low-iron float $1050^{\circ} \mathrm{C}$ " specimen, cast above the liquidus point then heat-treated below the crystallization peak showed less crushing and lateral cracking than its fast-cooled "Low-iron $1120^{\circ} \mathrm{C}$ " variant (Fig. 31). Such differences in the thermal history need to be systematically explored to identify how the different parameters affect the densification and crack propagation resistance mechanisms.

The variation in the results shows that the further exploration of surface treatments and the design of composite glasses (e.g., consisting of a more flexible surface yet a tougher core to stop crack propagation) is meaningful in creating less brittle cast glass components.

\section{Relevance of the Results to the Engineering Practice}

The splitting experiment intensifies -for testing purposes- a typical loading scenario in cast glass structures that involves the development of contact peak stresses. Cast components are often employed in compressive structures, where contact stresses are more critical than far-field stresses. Therefore, relying only on flexural strength data -a common approach in the engineering practice for the design and calculation of a glass structure- can lead to false estimations, as different defects and deformation mechanisms dominate the failure process during bending compared to compression. At this point it should be underlined that avoiding the direct contact of the glass components to other hard materials (e.g., glass, steel), with the use of a soft rubber interlayer for example, does not cancel the development of peak stresses. Oikonomopoulou (2019) has experimentally proven that during the compressive static loading of drystacked interlocking (osteomorphic) cast glass components with Polyurethane (PU) intermediaries, the creeping of the interlayer in combination with manufacturing unevenness in the cast components would lead to peak stresses and eventual failure of the glass components. Aurik et al. (2018) showed as well that, during the compression under a constant load of a column assembly out of orthogonal Poesia bricks with PU interlayers in between, the insufficient contact between

$\gamma=\frac{1}{2} \cdot\left(\frac{1}{V_{m}}\right)^{\frac{2}{3}} \cdot N^{\frac{1}{3}} \cdot\left\langle U_{o}\right\rangle$

where, $N$ is the Avogadro number and $U_{o}$ is the mean bond strength considered in the fracture process. From the formula it can be derived that strong bonds and small molar volumes increase the surface fracture energy.

${ }^{12}$ Fracture toughness is directly related to the fracture surface energy by the following formula, based on the work of Griffith (1921) and Irwin (1957):

$$
K_{I C}=\sqrt{\frac{2 \cdot E \cdot \gamma}{1-v^{2}}}
$$


the bricks (due to manufacturing tolerances) will lead to unexpected failures. It is therefore crucial to approach the engineering of cast glass structures in a more integral manner, considering as well the crack initiation and crack propagation resistance of glass, apart from its flexural/tensile strength. Although the splitting test cannot substitute the testing of a prototype section of the cast glass structure envisioned (this test should always take place at the final stages of the design), it can inform the initial steps of the design and choice of glass type.

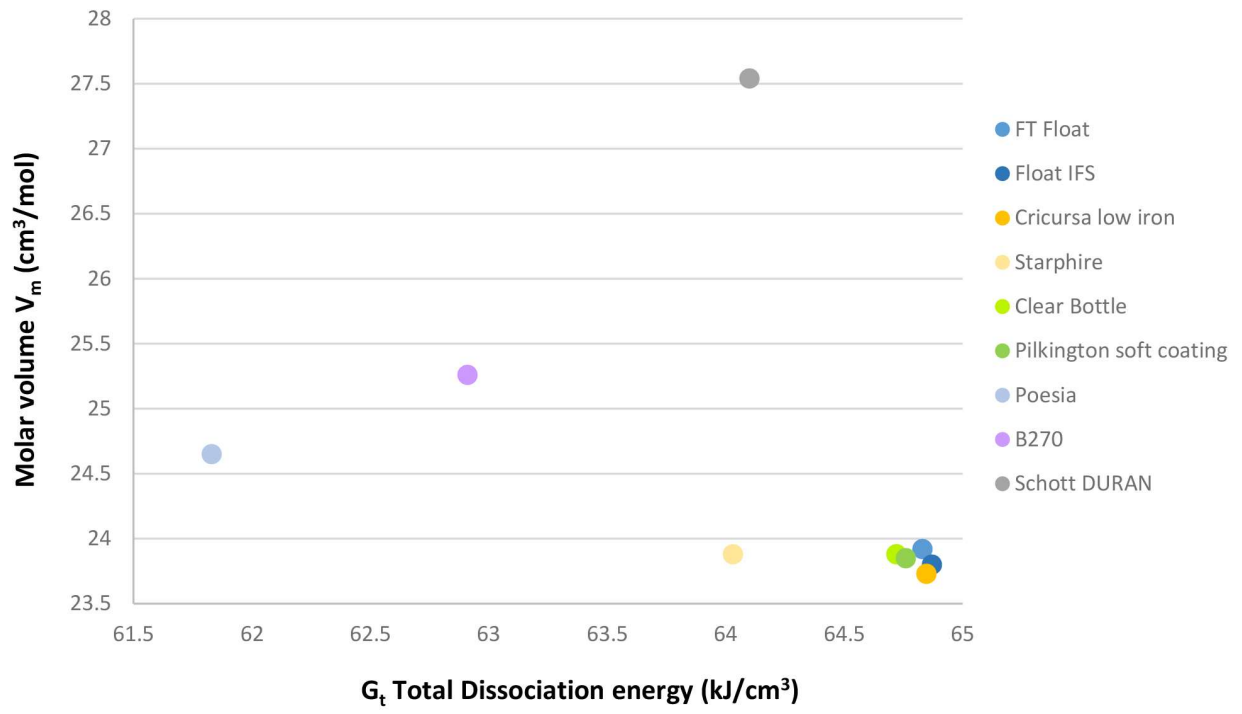

Fig. 30: Molar volume in relation to the bond strength (expressed as the Total Dissociation energy) for the glass compositions included in this study
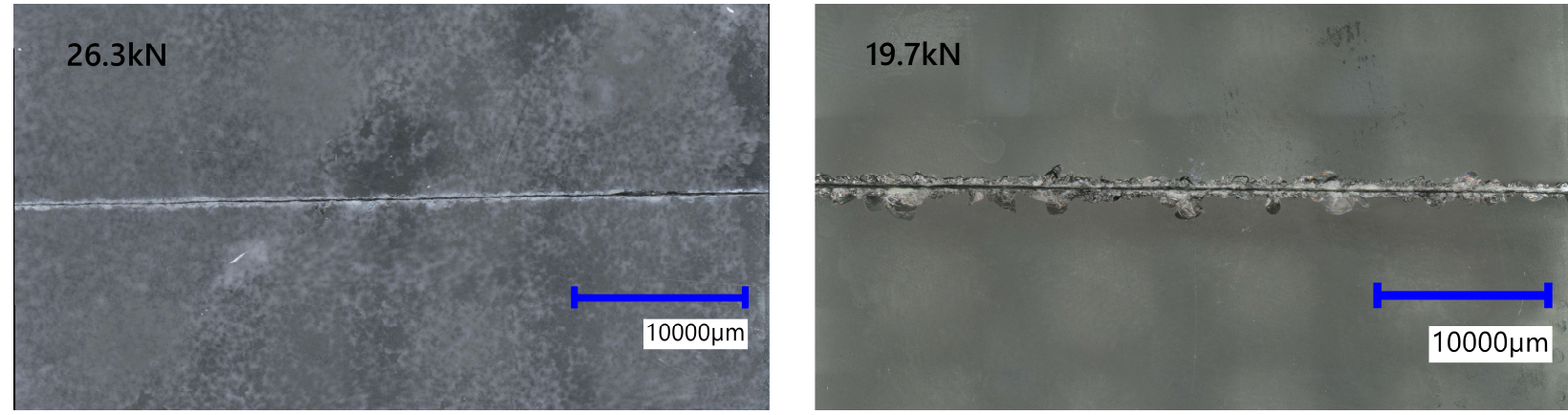

Fig. 31: Bottom surface of a heat-treated "Cricursa low-iron float" specimen (left) and a simply cooled and annealed "Cricursa $1120^{\circ} \mathrm{C}$ " specimen (right). Although the failure load of the heat-treated specimen was higher ( $26.3 \mathrm{kN}$ versus $\left.19.7 \mathrm{kN}\right)$, the extent of crushing $(70-140 \mu \mathrm{m})$ and lateral damage $(\max .747 \mu \mathrm{m})$ is significantly less than in the normal specimen, where the crushing zone extends from $200-360 \mu \mathrm{m}$ and the maximum lateral damage is $1837 \mu \mathrm{m}$

Table 4: Crack resistance, fracture toughness and hardness of soda lime and borosilicate glass, as reported in the literature

\begin{tabular}{|c|c|c|c|c|c|c|c|c|c|c|c|c|}
\hline \multirow[b]{2}{*}{ Glass type } & \multicolumn{7}{|c|}{ Composition (wt\%) } & \multirow{2}{*}{$\begin{array}{l}\mathrm{CR} \\
(\mathrm{N})\end{array}$} & \multirow{2}{*}{$\begin{array}{l}\mathrm{K}_{\mathrm{ic}} \\
\left(\mathrm{MPa} \cdot \mathrm{m}^{0.5}\right)\end{array}$} & \multirow{2}{*}{$\begin{array}{l}\mathrm{K}_{\text {Ic }} \text { test } \\
\text { method }\end{array}$} & \multirow{2}{*}{$\begin{array}{l}\mathrm{HV} \\
(\mathrm{GPa})\end{array}$} & \multirow[b]{2}{*}{ Source } \\
\hline & $\mathrm{SiO}_{2}$ & $\mathrm{~B}_{2} \mathrm{O}_{3}$ & $\mathrm{Na}_{2} \mathrm{O}$ & $\mathrm{K}_{2} \mathrm{O}$ & $\mathrm{CaO}$ & $\mathrm{MgO}$ & $\mathrm{Al}_{2} \mathrm{O}_{3}$ & & & & & \\
\hline \multirow[t]{3}{*}{ Soda lime silica } & 72.6 & & 13.8 & & 9.5 & 4.1 & & 0.70 & 0.74 & SEPB & 6.3 & {$[1]$} \\
\hline & 80.2 & & 10.4 & & 9.4 & & & 1.47 & 0.75 & SEPB & 5.6 & [2] \\
\hline & 78.3 & & 13.3 & 1.5 & 0.9 & 2.7 & 3.3 & 34.00 & 0.92 & IF & 4.7 & [3] \\
\hline \multirow[t]{3}{*}{ Borosilicate } & 79.2 & 13.3 & 5.4 & & & & 2.1 & 4.41 & $0.65 / 0.73$ & SEPB & 6.5 & {$[4],[5],[6]$} \\
\hline & 73.5 & 11.4 & 5.1 & & & & & 9.81 & 0.76 & SEPB & 6.1 & [2] \\
\hline & 65.6 & 21.9 & & 7.4 & & & & 12.75 & 0.73 & SEPB & 5.7 & {$[2]$} \\
\hline
\end{tabular}

[1] To et al. (2020); [2] Kato et al. (2010a); [3] Sehgal and Ito (1999); [4] Limbach et al. (2015); [5] To et al. (2018); [6] Quinn and Swab (2017) 
Telesilla Bristogianni et al. / International Journal of Structural Glass and Advanced Materials Research 2021, Volume 5: 195.225 DOI: 10.3844/sgamrsp.2021.195.225

Table 5: Vicker's hardness as reported in the literature for common chemical glass compositions

\begin{tabular}{|c|c|c|c|c|c|c|c|c|c|c|}
\hline \multirow[b]{2}{*}{ Glass type } & \multicolumn{10}{|c|}{ Composition (wt\%) } \\
\hline & $\mathrm{SiO}_{2}$ & $\mathrm{~B}_{2} \mathrm{O}_{3}$ & $\mathrm{Na}_{2} \mathrm{O}$ & $\mathrm{K}_{2} \mathrm{O}$ & $\mathrm{CaO}$ & $\mathrm{MgO}$ & $\mathrm{Al}_{2} \mathrm{O}_{3}$ & $\mathrm{H}_{\mathrm{v}}(\mathrm{GPa})$ & $\begin{array}{l}\text { Indentation } \\
\operatorname{load}(\mathrm{N})\end{array}$ & Source \\
\hline \multirow[t]{2}{*}{$\mathrm{a}-\mathrm{SiO}_{2}$} & 100.0 & & & & & & & 6.2 & $1-3$ & [1] \\
\hline & 100.0 & & & & & & & 8.7 & 1 & [2] \\
\hline \multirow[t]{3}{*}{ SLS } & 72.3 & & 12.5 & 1.60 & 8.5 & 3.4 & 1.7 & 5.4 & $1-3$ & [1] \\
\hline & 74.1 & & 12.2 & & 11 & 1.9 & 0.8 & 6.5 & 1 & [2] \\
\hline & 72.0 & & 12.9 & 0.40 & 9.9 & 4.0 & 0.8 & 6.3 & 1 & [2] \\
\hline Modified SLS & 76.8 & & 15.2 & & 4.6 & & 3.4 & 5.8 & $1-3$ & {$[1]$} \\
\hline \multirow[t]{2}{*}{ Borosilicate } & 81.9 & 12.5 & 4.0 & & & & 1.6 & 5.5 & $1-3$ & [1] \\
\hline & 79.7 & 14.1 & 5.3 & 0.95 & & & & 6.7 & 1 & [2] \\
\hline
\end{tabular}

[1] Sehgal and Ito (1999); [2] Sellappan et al. (2013)

Table 6: Surface energy and fracture toughness as reported in the literature

\begin{tabular}{|c|c|c|c|c|c|c|c|c|c|c|c|c|c|c|c|c|}
\hline \multirow[b]{2}{*}{ Glass type } & \multicolumn{7}{|c|}{ Composition (wt\%) } & \multirow{2}{*}{$\begin{array}{l}\text { Density } \\
\left(\mathrm{g} / \mathrm{cm}^{3}\right)\end{array}$} & \multirow{2}{*}{$\begin{array}{l}\mathrm{E} \\
(\mathrm{GPa})\end{array}$} & \multirow[b]{2}{*}{$v$} & \multirow[b]{2}{*}{$\mathrm{APF}$} & \multirow{2}{*}{$\begin{array}{l}\text { Theoretical } \\
\gamma\left(\mathrm{J} / \mathrm{m}^{2}\right)\end{array}$} & \multirow{2}{*}{$\begin{array}{l}\text { Measured } \\
\gamma\left(\mathrm{J} / \mathrm{m}^{2}\right), \\
\mathrm{N}_{2}(\mathrm{~g}), \\
300^{\circ} \mathrm{K} \\
\end{array}$} & \multirow{2}{*}{$\begin{array}{l}\mathrm{K}_{\mathrm{Ic}} \\
\left(\mathrm{MPa} \cdot \mathrm{m}^{0.5}\right)\end{array}$} & \multirow{2}{*}{$\begin{array}{l}\mathrm{K}_{\mathrm{Ic}} \text { measurement } \\
\text { method }\end{array}$} & \multirow[b]{2}{*}{ Source } \\
\hline & $\mathrm{SiO}_{2}$ & $\mathrm{~B}_{2} \mathrm{O}_{3}$ & $\mathrm{Na}_{2} \mathrm{O}$ & $\mathrm{K}_{2} \mathrm{O}$ & $\mathrm{CaO}$ & $\mathrm{MgO}$ & $\mathrm{Al}_{2} \mathrm{O}_{3}$ & & & & & & & & & \\
\hline \multirow{3}{*}{$\mathrm{a}-\mathrm{SiO}_{2}$} & 100 & & & & & & & 2.2 & 70 & 0.15 & 0.456 & 3.62 & & 0.73 & DCC (vacuum) & {$[1]$} \\
\hline & 99.8 & & & & & & & & 72.1 & & & & $4.32-4.42$ & $0.79-0.8$ & $\operatorname{DCC}\left(\mathrm{N}_{2}(\mathrm{~g}), 300^{\circ} \mathrm{K}\right)$ & [2] \\
\hline & 100 & & & & & & & & 73 & 0.16 & & & & 0.93 & $\operatorname{SEPB}\left(\mathrm{N}_{2}\right)$ & [3] \\
\hline \multirow[t]{3}{*}{ SLS } & 71 & & 13 & & 10 & 6 & & 2.49 & 72 & 0.22 & 0.496 & 3.55 & & $0.68-0.72$ & CN-SEPB & [1] \\
\hline & 72 & & 14 & 1 & 7 & 4 & 2 & & 73.4 & & & & $3.82-3.91$ & $0.75-0.76$ & $\operatorname{DCC}\left(\mathrm{N}_{2}(\mathrm{~g}), 300^{\circ} \mathrm{K}\right)$ & {$[2]$} \\
\hline & $70-74$ & & $12-16$ & $0-0.5$ & $8-13$ & $0-5$ & $0-2$ & & 72 & 0.22 & & & & 0.76 & $\operatorname{SEPB}\left(\mathrm{N}_{2}\right)$ & [3] \\
\hline \multirow{3}{*}{ Borosilicate } & 81 & 13 & 4 & & & & 2 & 2.23 & 63.7 & 0.20 & 0.478 & 3.88 & & 0.68 & $\mathrm{CN}$ & [1] \\
\hline & 80 & 14 & 4 & & & & 2 & & 63.7 & & & & $4.51-4.75$ & $0.76-0.78$ & $\operatorname{DCC}\left(\mathrm{N}_{2}(\mathrm{~g}), 300^{\circ} \mathrm{K}\right)$ & [2] \\
\hline & 81 & 13 & 4 & 4 & & & 2 & & 64 & 0.20 & & & & 0.75 & $\operatorname{SEPB}\left(\mathrm{N}_{2}\right)$ & [3] \\
\hline $\mathrm{a}-\mathrm{B}_{2} \mathrm{O}_{3}$ & & 100 & & & & & & 1.85 & 17.4 & 0.26 & 0.495 & 4.99 & & $0.95-1.3$ & IF-SENB & [1] \\
\hline
\end{tabular}

[1] Rouxel and Yoshida (2017); [2] Wiederhorn (1969); [3] Quinn and Swab (2017)

Also important is to shift the attention of structural engineers from the concept of glass strength to that of "glass flexibility". High hardness and stiffness does not guarantee a long-lasting glass structure; it is rather the low brittleness (high crack initiation load) or larger scratch resistance according to Sehgal and Ito (1999). This is directly evident by the brittleness $(B)$ formula ${ }^{13}$ proposed by Quinn and Quinn (1997), which can predict wear:

$B=\frac{H \cdot E}{\left(K_{I C}\right)^{2}}$

Thus the ability of a glass to resist surface damage by accommodating contact stresses by deformation, reduces the appearance of cracks, prolonging in that manner its service life.

\section{Conclusion}

This study aims to investigate the fracture resistance of cast glass by means of a customized splitting test. For the purposes of the splitting test, triplets of $50 \mathrm{~mm}$ cubic specimens are kiln-cast using various different glass cullet types and firing schedules. According to the cullet specifications and imposed thermal history, different

${ }^{13}$ Various formulas exist for quantifying the brittleness of ceramics, with the one developed by Lawn and Marshall (1979) being the most widely used: inhomogeneities such as bubble veils, cord, crystalline interfaces or randomly spread stones appear in the glass, which are often linked with the creation of internal stress. The splitting test reveals information about the resistance of glass to catastrophic fracture but also about the influence of the occurring flaws in the bulk to the overall structural performance of the glass.

The tests show that the borosilicate specimens $\left(1120^{\circ} \mathrm{C}, 970^{\circ} \mathrm{C}\right)$ fail at the highest splitting force, followed by the soda lime float specimens $\left(1120^{\circ} \mathrm{C}\right)$, while the fused or porous specimens have a significantly lower resistance to fracture. The ranking of the different glass compositions based on the splitting test is contradictory to the results of previously conducted fourpoint bending tests in cast glass specimens of similar composition and thermal profile. This occurs because different fracture mechanisms are highlighted when a glass specimen is subjected to a contract stress (sharp toolbit) and to a far-field stress (bending). More specifically, the fracture resistance of the glass specimens is governed, first by the ability of the glass to deform around the pressing sharp toolbit in order to relief the stresses and then by the bond strength of the glass and the quality of the glass network (e.g., network non damaged/broken by inclusions and flaws). For a high resistance to fracture, a good balance between glass

$B=\frac{H}{K_{I C}}$ 
network flexibility (sufficient empty space in molecular level) and high bond dissociation energy is required. The tested borosilicate glass may have a lower stiffness than soda lime float glass -which is reflected to its lower flexural strength- yet its higher molar volume and higher fracture surface energy allow for a higher fracture resistance. On the other hand, the low molar volume in combination with low dissociation energy characterizing the Poesia glass, leads to a much lower resistance to fracture. The contradictory results between different testing methods, highlight the fact that relying on flexural strength data alone is not sufficient for the safe and reliable engineering of cast glass structures.

By studying the manner the crack propagates through the material, the influence of the defects situated in the bulk on the structural performance can be observed. Overall, bubble veils and cord situated in parallel to the crack front, do not form weak zones to the extent of altering the path of a fast moving crack. In a similar fashion, perpendicular to the crack front crystalline interfaces, may momentarily arrest the crack but are not found sufficient of completely ceasing the catastrophic propagation of the crack. The encountered flaws in the bulk, as long as they are not inducing stresses that lead to immediate fracture upon cooling, they are neither deteriorating nor improving the properties of the glass components to a significant level. If such defects are not situated at the process zone around the toolbit, they seem to have a negligible contribution to the fracture resistance of the glass specimens. In other words, inhomogeneous zones can exist in the bulk of the glass component, without significantly affecting its mechanical properties, as long as they are not exposed to tensile stresses above the tolerable maximum.

\section{Recommendations}

This study involved a minimum number of tested specimens, being indicative for the fracture resistance of cast glass but not conclusive. For obtaining reliable statistical data, extended testing is suggested. To increase the accuracy of the results, fine polished and perfectly parallel bottom and top surfaces are required to avoid misalignments of the specimens with the toolbit and loading head. This should allow to detect minor differences in the performance which are caused by the use of different chemical compositions or thermal profiles (e.g., a slower cooling leading to a more densified network). Also testing of the specimens at different loading rates is advised, as a faster rate will probably lead to a reduced fracture resistance. In addition, the subjection of the cubes to a constant load that can lead to eventual slow crack growth (in combination with environmental humidity) and failure, may reveal different information about the interaction of the inhomogeneities in the bulk with the crack path. Finite element analysis should be conducted in parallel to the physical experiments, in order to quantify the ultimate tensile strength that develops around the toolbit.

The splitting test is advised to be combined with micro-hardness and fracture toughness experiments. These tests will help to determine the contribution of each mechanical property to the fracture resistance of the cast glasses and therefore engineer cast glasses of higher fracture resistance.

Further experimentation is required regarding the heating, cooling and annealing schemes followed and the glass properties obtained. It is worth exploring, for example, if a much thicker crystalline zone in the middle of a specimen can arrest a propagating crack travelling perpendicular to it. Or if a faster cooling scheme can add more "flexibility" to the external surface due to the more open space in a molecular scale. As the defects in the mesostructure seem to have a minimal role in comparison to the critical role of the surface, efforts in improving or even strengthening the surface of cast glass become crucial for ensuring safe and strong structural components. Various techniques can be investigated such as the chemical or heat-treatment of the surface or the application of a purer/stronger/more flexible glass around a weaker contaminated core. The splitting test is a relatively easy and fast testing method that can detect differences in the surface quality and help in this process of identifying the most suitable strengthening methods and designing efficient composite glasses.

\section{Acknowledgement}

The authors would like to thank Rong $\mathrm{Yu}$ and Tommaso Venturini for assisting with the preparation of the glass specimens and Ruud Hendrikx and his team for conducting the XRF and XRD analyses. We are also grateful to George Quinn and James Varner for the meaningful discussions regarding the interpretation of the splitting test and the fractured surfaces and to Bert Sluijs for his guidance and suggestions in this study. In addition, we are very thankful to Henning Katte and Daniel Schreinert for sponsoring the use of the Ilis StrainScope Flex Polariscope. Lastly we would like to express our gratitude to Ewald Jooste (Cricursa), Hans van Limpt and Bart Wilms (Sibelco), Bianca Lambrechts and Danny Timmers (Maltha) and Martijn Rietveld (NSG Pilkington) for providing us with cullet material for our experiments.

\section{Ethics}

This article is original and contains unpublished material. The corresponding author confirms that all authors have read and approved the manuscript and no ethical issues involved. 


\section{References}

Abrisa Technologies. (2014). SCHOTT Duran ${ }^{\circledR}$ Lab Glass (Tubed). Abrisa Technologies. abrisatechnologies.com/products-services/glassproducts/borosilicate/schott-duran/

Anagni, G. M., Mazzucchelli, E. S., Rigone, P., Bristogianni, T., \& Oikonomopoulou, F. (2020). Recycled glass mixtures as cast glass components for structural applications, towards sustainability. Challenging Glass, 7, 1-14. https://re.public.polimi.it/handle/11311/1145316\#.Y KYmX6gzaUk

ASTM C 496. (2011). Standard Test Method for Splitting Tensile Strength of Cylindrical Concrete Specimens. US, ASTM: Designation: C496/C496M-11. www.astm.org/Standards/C496

Aurik, M., Snijder, A., Noteboom, C., Nijsse, R., \& Louter, C. (2018). Experimental analysis on the glass-interlayer system in glass masonry arches. Glass Structures \& Engineering, 3(2), 335-353. https://doi.org/ 10.1007/s40940-018-0068-7

Bristogianni, T., Oikonomopoulou, F., Yu, R., Veer, F. A., \& Nijsse, R. (2020). Investigating the flexural strength of recycled cast glass. Glass Structures \& Engineering, 5(3), 445-487.

https://doi.org/10.1007/s40940-020-00138-2

Bristogianni, T., Oikonomopoulou, F., \& Veer, F. A. (2021). On the flexural strength and stiffness of cast glass. Accepted for publication in Glass Structures \& Engineering. DOI: 10.1007/s40940-021-00151-z

Fluegel, A. (2007a). Global model for calculating roomtemperature glass density from the composition. Journal of the American Ceramic Society, 90(8), 2622-2625. https://doi.org/10.1111/j.1551-2916.2007.01751.X

Fluegel, A. (2007b). Glass viscosity calculation based on a global statistical modelling approach. Glass Technology-European Journal of Glass Science and Technology Part A, 48(1), 13-30. https://www.ingentaconnect.com/content/sgt/gta/200 7/00000048/00000001/art00003

Gopalakrishnan, K., \& Mecholsky, J. J. (2014). Quantitative fractography of mixed mode fracture in glass and ceramics. Journal of the European Ceramic Society, 34(14), 3247-3254. https://doi.org/10.1016/j.jeurceramsoc.2014.03.019

Griffith, A. A. (1921). VI. The phenomena of rupture and flow in solids. Philosophical transactions of the royal society of London. Series A, Containing Papers of a Mathematical or Physical Character, 221(582-593), 163-198. https://doi.org/10.1098/rsta.1921.0006

Gross, T. M., \& Tomozawa, M. (2008). Fictive temperature-independent density and minimum indentation size effect in calcium aluminosilicate glass. Journal of Applied Physics, 104(6), 063529. https://doi.org/10.1063/1.2985907
Hasdemir, I., Striepe, S., Deubener, J., \& Simon, K. (2015). A 2000-year perspective on indentation crack resistance and brittleness of glass. Journal of NonCrystalline Solids, 408, 51-56. https://doi.org/10.1016/j.jnoncrysol.2014.10.012

Heimerl, W., Baucke, F. G., Brix, P., \& Conradt, R. (1999). Chemical resistance and corrosion and ion release. In Analysis of the Composition and Structure of Glass and Glass Ceramics (pp. 399-450). Springer, Berlin, Heidelberg. https://doi.org/10.1007/978-3662-03746-1

Heraeus Holding. (2013). Challenges in semiconductor manufacturing. www.base-materials.heraeusquarzglas.com

Inaba, S., Fujino, S., \& Morinaga, K. (1999). Young's modulus and compositional parameters of oxide glasses. Journal of the American Ceramic Society, 82(12), 3501-3507. https://doi.org/10.1111/j.11512916.1999.tb02272.x

Irwin, G. R. (1957). Analysis of Stresses and Strains near the End of a crack Traversing a Plate. Journal of Applied Mechanics, 24, 361-364. https://www.scirp.org/(S(351jmbntvnsjt1 aadkposzje ) )/reference/ReferencesPapers.aspx?ReferenceID=1 03965

Ito, S., \& Taniguchi, T. (2004). Effect of cooling rate on structure and mechanical behavior of glass by MD simulation. Journal of Non-Crystalline Solids, 349, 173-179. https://doi.org/10.1016/j.jnoncrysol.2004.08.180

Januchta, K., \& Smedskjaer, M. M. (2019). Indentation deformation in oxide glasses: Quantification, structural changes and relation to cracking. Journal of Non-Crystalline Solids: X, 1, 100007-100007. https://doi.org/10.1016/j.nocx.2018.100007

Januchta, K., Liu, P., Hansen, S. R., To, T., \& Smedskjaer, M. M. (2020). Indentation cracking and deformation mechanism of sodium aluminoborosilicate glasses. Journal of the American Ceramic Society, 103(3), 1656-1665. https://doi.org/10.1111/jace.16894

Kato, Y., Yamazaki, H., Kubo, Y., Yoshida, S., Matsuoka, J., \& Akai, T. (2010a). Effect of B2O3 content on crack initiation under Vickers indentation test. Journal of the Ceramic Society of Japan, 118(1381), 792-798. https://doi.org/10.2109/jcersj2.118.792

Kato, Y., Yamazaki, H., Yoshida, S., \& Matsuoka, J. (2010b). Effect of densification on crack initiation under Vickers indentation test. Journal of NonCrystalline Solids, 356(35-36), 1768-1773. https://doi.org/10.1016/j.jnoncrysol.2010.07.015

Kschinka, B. A., Perrella, S., Nguyen, H. C. B. R., \& Bradt, R. C. (1986). Strengths of glass spheres in compression. Journal of the American Ceramic Society, 69(6), 467-472. https://doi.org/10.1111/j.1151-2916.1986.tb07447.x 
Lawn, B. R., \& Marshall, D. B. (1979). Hardness, toughness and brittleness: an indentation analysis. Journal of the American Ceramic Society, 62(7-8), 347-350. 2916.1979.tb19075.x https://doi.org/10.1111/j.1151-

Lei, C. (2019). Structural cast glass-ceramic components: The potential of recycling soda-lime-silica glass into cast glass-ceramic components and its mechanical behaviour. Delft University of Technology. http://resolver.tudelft.nl/uuid:f9a77112-cbe7-445ba9fe-36285f3b9381

Limbach, R., Winterstein-Beckmann, A., Dellith, J., Möncke, D., \& Wondraczek, L. (2015). Plasticity, crack initiation and defect resistance in alkaliborosilicate glasses: from normal to anomalous behavior. Journal of Non-Crystalline Solids, 417, 15-27. https://doi.org/10.1016/j.jnoncrysol.2015.02.019

Makishima, A., \& Mackenzie, J. D. (1973). Direct calculation of Young's moidulus of glass. Journal of Non-Crystalline Solids, 12(1), 35-45. https://doi.org/10.1016/0022-3093(73)90053-7

Makishima, A., \& Mackenzie, J. D. (1975). Calculation of bulk modulus, shear modulus and Poisson's ratio of glass. Journal of Non-Crystalline Solids, 17, 147-157. https://doi.org/10.1016/0022-3093(75)90047-2

Mellor, M., \& Hawkes, I. (1971). Measurement of tensile strength by diametral compression of discs and annuli. Engineering Geology, 5(3), 173-225. https://doi.org/10.1016/0013-7952(71)90001-9

Nakamura, H. (2012). NAP: Optical Glass House. www.nakam.info/en/works/optical-glass-house/

Nakayama, J. (1965). Direct measurement of fracture energies of brittle heterogeneous materials. Journal of the American Ceramic Society, 48(11), 583-587. https://doi.org/10.1111/j.1151-2916.1965.tb14677.x

Nyounguè, A., Bouzid, S., Dossou, E., \& Azari, Z. (2016). Fracture characterisation of float glass under static and dynamic loading. Journal of Asian Ceramic Societies, 4(4), 371-380. https://doi.org/10.1016/j.jascer.2016.07.004

Oikonomopoulou, F., Bristogianni, T., Veer, F. A., \& Nijsse, R. (2018a). The construction of the Crystal Houses façade: challenges and innovations. Glass Structures \& Engineering, 3(1), 87-108. https://doi.org/10.1007/s40940-017-0039-4

Oikonomopoulou, F., Bristogianni, T., Barou, L., Veer, F. A., \& Nijsse, R. (2018b). The potential of cast glass in structural applications. Lessons learned from large-scale castings and state-of-the art load-bearing cast glass in architecture. Journal of Building Engineering, 20, 213-234. https://doi.org/10.1016/j.jobe.2018.07.014

Oikonomopoulou, F. (2019). Experimental and numerical investigation of an interlocking system out of osteomorphic cast glass components. A+ BE| Architecture and the Built Environment, (9), 247-296. https://doi.org/10.7480/abe.2019.9
Paech, C., \& Goppert, K. (2008). Innovative Glass JointsThe 11 March Memorial in Madrid. In Challenging Glass: Conference on Architectural and Structural Applications of Glass (pp. 111-118). ISBN: 9781586038663

Parascho, S., Han, I. X., Walker, S., Beghini, A., Bruun, E. P., \& Adriaenssens, S. (2020). Robotic vault: a cooperative robotic assembly method for brick vault construction. Construction Robotics, 4(3), 117-126. https://doi.org/10.1007/s41693-020-00041-w

Quinn, G. D., \& Swab, J. J. (2017). Fracture toughness of glasses as measured by the SCF and SEPB methods. Journal of the European Ceramic Society, 37(14), 4243-4257. https://doi.org/10.1016/j.jeurceramsoc.2017.05.012

Quinn, J. B., \& D Quinn, G. (1997). Indentation brittleness of ceramics: a fresh approach. Journal of Materials Science, 32(16), 4331-4346. https://doi.org/10.1023/A:1018671823059

Rouxel, T. (2008, May). Designing glasses to meet specific mechanical properties. In Challenging Glass: Conference on Architectural and Structural Applications of Glass, Faculty of Architecture, Delft University of Technology, May 2008 (Vol. 39). IOS Press. https://core.ac.uk/download/pdf/228662869.pdf

Rouxel, T. (2017). Fracture surface energy and toughness of inorganic glasses. Scripta Materialia, 137, 109-113. https://doi.org/10.1016/j.scriptamat.2017.05.005

Rouxel, T., \& Yoshida, S. (2017). The fracture toughness of inorganic glasses. Journal of the American Ceramic Society, 100(10), 4374-4396. https://doi.org/10.1111/jace.15108

Schott. (2013). Schott: B 270 ${ }^{\circledR}$ i. www.schott.com/enus/products/b-270

Schott. (2015). Schott: Tubular Glass Photobioreactors. www.schott.com/tubing/english/special_glass/indust ry_environment/pbr.html

Schott. (2017). Schott: DURAN Technical Data. www.schott.com/d/tubing/9d60ae04-a9db-4b6382b3-7aebd5bad71e/1.6/schotttubing_brochure_duran_english-en.pdf

Sehgal, J., \& Ito, S. (1999). Brittleness of glass. Journal of Non-Crystalline Solids, 253(1-3), 126-132. https://doi.org/10.1016/S0022-3093(99)00348-8

Sellappan, P., Rouxel, T., Celarie, F., Becker, E., Houizot, P., \& Conradt, R. (2013). Composition dependence of indentation deformation and indentation cracking in glass. Acta Materialia, 61(16), 5949-5965. https://doi.org/10.1016/j.actamat.2013.06.034

Shannon, R. D. (1976). Revised effective ionic radii and systematic studies of interatomic distances in halides and chalcogenides. Acta Crystallographica, 32(5), 751-767. https://doi.org/10.1107/S0567739476001551 
Sheikh, M. Z., Wang, Z., Du, B., Suo, T., Li, Y., Zhou, F., ... \& Wang, Y. (2019). Static and dynamic Brazilian disk tests for mechanical characterization of annealed and chemically strengthened glass. Ceramics International, 45(6), 7931-7944. https://doi.org/10.1016/j.ceramint.2019.01.106

To, T., Célarié, F., Roux-Langlois, C., Bazin, A., Gueguen, Y., Orain, H., ... \& Rouxel, T. (2018). Fracture toughness, fracture energy and slow crack growth of glass as investigated by the Single-Edge Precracked Beam (SEPB) and Chevron-Notched Beam (CNB) methods. Acta Materialia, 146, 1-11. https://doi.org/10.1016/j.actamat.2017.11.056

To, T., Jensen, L. R., \& Smedskjaer, M. M. (2020). On the relation between fracture toughness and crack resistance in oxide glasses. Journal of NonCrystalline Solids, 534, 119946. https://doi.org/10.1016/j.jnoncrysol.2020.119946

Vitro Architectural Glass. (2020). Starphire ${ }^{\circledR}$ Technical Product Data.

www.vitroglazings.com/media/gpvmzllx/vitrostarphire-vitro-technical-pds.pdf
Wada, M., Furukawa, H., \& Fujita, K. (1974). Crack resistance of glass on Vickers indentation. In Proceedings of the 10th International Congress on Glass (pp. 39-46).

Wiederhorn, S. M. (1969). Fracture surface energy of glass. Journal of the American Ceramic Society, 52(2), 99-105. https://doi.org/10.1111/j.11512916.1969.tb13350.x

Yamane, M., \& Mackenzie, J. D. (1974). Vicker's hardness of glass. Journal of non-crystalline solids, 15(2), 153-164. https://doi.org/10.1016/00223093(74)90044-1

Yun, Y. H., \& Bray, P. J. (1978). Nuclear magnetic resonance studies of the glasses in the system $\mathrm{Na}_{2} \mathrm{O} \cdot \mathrm{B}_{2} \mathrm{O}_{3} \cdot \mathrm{SiO}_{2}$. Journal of Non-Crystalline Solids, 27(3), 363-380. https://doi.org/10.1016/00223093(78)90020-0 